\title{
ANÁLISE DOS ÍNDICES DE INOVAÇÃO E OS RESULTADOS RECENTES DA BALANÇA COMERCIAL BRASILEIRA
}

\author{
ANALYSIS OF THE INNOVATION INDICES AND THE RECENT RESULTS OF THE BRAZILIAN \\ TRADE BALANCE
}

\author{
Willian Ramires Pires Bezerra \\ willramires@gmail.com \\ Universidade Federal de Pernambuco, Pernambuco, Brasil \\ http:/ / orcid.org/0000-0001-7300-6444
}

\author{
Nelson da Cruz Monteiro Fernandes \\ cruzfernandes55@gmail.com \\ Universidade Federal de Pernambuco, Pernambuco, Brasil \\ http:/ / orcid.org/0000-0002-1662-9300
}

\begin{abstract}
Resumo
O objetivo deste artigo é analisar o índice de inovação com os resultados da balança comercial brasileira no período de 2008 a 2018. A partir de uma pesquisa de natureza qualitativa, descritiva, bibliográfica e documental foram auferidos os avanços pontuais das políticas públicas de CT\&I no período estudado. Persistem avanços tímidos e estagnações entre os indicadores estudados como investimento em P\&D, qualificação profissional, desenvolvimento de novos conhecimentos, proteção industrial, percepção do valor pela inovação. Esses dados desabonadores se reproduzem na balança comercial, todavia, rotas de solução foram aqui observadas.
\end{abstract}

Palavras-chave: Balança Comercial. Conhecimento. Propriedade industrial. Inovação.

\begin{abstract}
The objective of this article is to analyze the innovation index with the results of the Brazilian trade balance in the period from 2008 to 2018. From a qualitative, descriptive, bibliographic and documentary research, the following results were obtained: punctual advances in public CT\&I policies in the period studied. Timid advances and stagnations persist among the indicators studied, such as investment in $R \& D$, professional qualification, development of new knowledge, industrial protection, perception of value through innovation. These disappointing data are reproduced in the trade balance, however, solution routes were observed here.
\end{abstract}

Keywords: Trade Balance. Knowledge. Industrial property. Innovation. 


\section{Introdução}

A competividade e o desenvolvimento econômico sustentável de longo prazo não são frutos apenas da combinação de forças produtivas e recursos, sejam eles materiais (máquinas, equipamentos e infraestrutura, por exemplo) ou imateriais (conhecimento e recursos naturais). O êxito dessa base material e de conhecimento depende da entrada em cena da atividade da inovação, da perturbação do equilíbrio que altera e desloca para sempre o status quo ante a produção, tecnologia, investimento, transporte e demanda (XIAO, 2020; KEKLIK, 2018; SCHUMPETER, 1984, 1997).

Para Deloitte (2015); Deleidi; Mazzucato (2021) ao longo das três primeiras revoluções industriais $\left(1^{\mathrm{a}}\right.$ revolução no final do século XVIII; $2^{a}$ revolução no início do século XX; $3^{a}$ revolução no início da década de 70) foi fundamental a contribuição da inovação na competitividade das empresas e consequentemente da formação de riqueza dos países. Já na $4^{a}$ revolução industrial o desenvolvimento econômico sustentável passou a fazer parte dos discursos dos principais atores do desenvolvimento capitalista, impactando na formulação das políticas públicas dos gestores e líderes. Hoje os Estados são chamados a desenvolver políticas de inovação que alcancem todas as empresas, desenvolvendo o espírito empreendedor e adotando ações de disseminação da propriedade intelectual que suportem a geração de riqueza, empregos, a elevação dos padrões de qualidade de vida e preservação do meio ambiente (BADRAN, BAYDOUN, HILLMAN, 2020; WEF, 2018, Deleidi; Mazzucato (2021). Os estados devem implementar um mix de variáveis que podem instrumentalizar e induzir o setor empresarial a incorporar atividades inovativas de maior risco e incerteza, induzindo mudanças no comportamento das empresas.

Nessa linha de raciocínio Furtado (2013), Julien (2017) e Arocena; Göransson; Sutz (2017) entendem que a consolidação das bases de uma economia nacional passa pela industrialização que auxilia na superação do subdesenvolvimento e incrementa competitividade, além de demandar tecnologia de ponta e empreendedora, principalmente quando se pretende superar o subdesenvolvimento no Sul Global. Furtado (2013) ainda acrescenta que nenhum sistema industrial capitalista pode existir sem mecanismos de coordenação e centros de decisão capazes de prever e tratar as interferências do ambiente externo, como do ambiente interno, constituída por variáveis sociais, políticas e ambientais (BADRAN, BAYDOUN, HILLMAN, 2020; CNI, 2016; JULIEN, 2017; BELDERBOS; DUVIVIER; WYNEN, 2009).

No Brasil, desde o final da década de 1990, ocorreram diversas políticas públicas orientadas para a promoção do sistema de Ciência, Tecnologia e Inovação (CT\&I), como mostram os levantamentos de De Negri (2017). O objetivo macro foi de fomentar o desenvolvimento do conhecimento, da tecnologia nacional e promover a inovação nos diversos setores do país dentro do contexto de um Sistema Nacional de Inovação (SNI) (RAMOS, 2018; CIRANI; CAMPANÁRIO; SILVA, 2015; MENDES; OLIVEIRA; PINHEIRO, 2013). De fato, nas últimas décadas o governo brasileiro desenvolveu esforços na consolidação do SNI, buscando fortalecer as instituições de pesquisa desde sua infraestrutura, como na formação dos pesquisadores (FACCIN; BORTOLASO; BALESTRIN, 2016), passando pelo financiamento direto dos projetos de inovação através de recursos a fundo perdido como também com linhas de financiamento a juros subsidiados. Ainda, buscou incentivar o setor produtivo a investir em pesquisa, desenvolvimento e inovação através de leis de incentivo fiscal (Lei do Bem no 11.195/2005, por exemplo) e também com a Lei de Inovação $\mathrm{n}^{\circ}$ 10.973/2004 e suas atualizações, avançando positivamente em vários aspectos, fomentando a parceria público e privado (PARANHOS; CATALDO; PINTO, 2018; IPEA, 2017; MENDES; OLIVEIRA; PINHEIRO, 2013).

Dentro deste contexto a proposta da pesquisa é analisar se na última década (2008-2018) a competitividade nacional no mercado externo foi minimamente alavancada pelas políticas públicas adotadas. Para isso vamos cruzar as informações a respeito dos avanços nos indicadores de CT\&I, evidenciando uma mínima relação de causa-efeito das políticas públicas de CT\&I e os resultados da 
balança comercial brasileira com olhar nos produtos da indústria de alta e de média-alta tecnologia no período.

\section{Cruzando os conceitos de inovação, competitividade e balança comercial}

Políticas econômicas estratégicas de fomento tem um efeito multiplicador no crescimento econômico de uma nação. A partir da combinação de forças produtivas e recursos, sejam eles materiais (máquinas, equipamentos e infraestrutura, por exemplo) ou imateriais (conhecimento e recursos naturais) se alcança a almejada competividade global da economia. Nesse cenário, o desenvolvimento econômico sustentável está fortemente calçada na inovação, ou seja, a perturbação do equilíbrio que altera e desloca para sempre o status quo ante da produção e ou do produto (KEKLIK, 2018; SCHUMPETER, 1984, 1997).

Hoje os Estados são chamados a desenvolver políticas de inovação que alcancem todas as empresas, desenvolvendo o espírito empreendedor e adotando ações de disseminação da propriedade intelectual que suportem a geração de riqueza, empregos, a elevação dos padrões de qualidade de vida e preservação do meio ambiente (WEF, 2018).

A palavra "inovação" se popularizou nos diversos setores da economia e administração através do economista Joseph Schumpeter primeiramente em seu livro "The Theory of Economic Development" (1934) onde defende que a fonte primeira da atividade inovadora é a operação de pequenas e médias empresas em setores altamente competitivos, privilegiando a figura do empreendedor visionário, e depois, em seu livro Capitalism, Socialism and Democracy (1942) descreve um padrão de inovação que tem como sustentação grandes empresas operando em mercados oligopolistas, destacando aqui os laboratórios de Pesquisa e Desenvolvimento (P\&D) como os principais motores da inovação (XIAO, 2020; KEKLIK, 2018; TIDD; BESSANT; 2015). Schumpeter insere o termo "destruição criativa" para elucidar a constante busca pela criação de algo novo que indubitavelmente destrói as velhas regras e estabelece outras novas. A concorrência que se observa no seio da economia capitalista é a de novos bens, novas tecnologias, novas fontes de insumos, novos modos de organização, sempre com o objetivo final de obter novas fontes de lucratividade e competitividade. (SCHUMPETER, 1984, 1997).

O cenário atual está em favor daquelas organizações que conseguem mobilizar conhecimento e avanços tecnológicos e que conseguem pôr em prática a criatividade em suas ofertas de produtos/serviços e até nas formas em que as lançam no mercado (CNI, 2016, 2017; TIDD; BESSANT, 2015; MASON; BISHOP; ROBISON, 2009). Nesses termos, a competitividade econômica de um país está intrinsicamente ligada a realidade do seu sistema de inovação, da sua cadeia produtiva e da sua infraestrutura, ou seja, a realidade da base interna em que as empresas irão construir seus processos de produção, inovação e competitividade (CASSIOLATO; LASTRES, 2017; CNI, 2016).

Essa competitividade é alcançada quando, de acordo com Julien (2017) e Furtado (2013), se fortalece as bases da economia nacional para superar o subdesenvolvimento e incrementa competitividade econômica, industrial e empresarial de um país, além de demandar tecnologia de ponta, com proteção de propriedade intelectual, e a formação de mão de obra qualificada e empreendedora. Para Furtado (2013) e Arocena, Göransson; Sutz (2017) esse esforço é realizado com base mecanismos de coordenação, centros de decisão, capazes de prever e tratar as interferências do ambiente externo, de outras economias, como do ambiente interno, constituída por variáveis sociais, políticas e ambientais. Dessa forma, é por meio do desenvolvimento das capacidades produtivas e tecnológicas na atividade industrial permitem elevar a capacidade de exportação de um país para competir no mercado internacional (JULIEN, 2017; TERRA, 2012; BELDERBOS; DUVIVIER; WYNEN, 2009).

Apesar de na última década, em termos de resultados médios acumulados, a economia brasileira e a participação da sociedade terem passado por uma transformação importante no que tange a inclusão 
social, na distribuição de renda e no mercado de trabalho, não podemos negar a fragilidade da competitividade da indústria nacional quando comparamos com as de outros países, principalmente relacionado com os produtos da indústria de transformação de alto valor agregado e tecnológico (produtos de alta e de média-alta intensidade tecnológica), como demostrado pela participação desta indústria no PIB e o resultado histórico na balança comercial brasileira (CASSIOLATO; LASTRES, 2017; COSTA, 2020).

Desde o início da década de 90 o modelo de desenvolvimento implantado no Brasil baseia-se no crescimento e fortalecimento da participação do país no processo de globalização, com a instalação em nosso território de grandes empresas multinacionais, justificando esta política como a forma mais rápida de informatizar ou de evoluir tecnologicamente nosso país. Como resultado, trouxe consigo o aumento do estoque de capital estrangeiro sem prover a inserção comercial brasileira no estrangeiro (exportação) e a extinção continuada das nossas empresas, promovendo a desindustrialização e com reflexo direto na balança comercial (CASSIOLATO; LASTRES, 2017; HIRATUKA; SARTI, 2017; SARTI; HIRATUKA, 2016).

A balança comercial é o registro do impacto de tudo que foi importado versus o que foi exportado, seja de produtos ou de serviços entre países. Reflete a diferença entre o que o país arrecadou com as exportações e o que gastou com importações (RODRIGUES, 2012). Serve como indicador para o cálculo do nível de risco de mercado para futuros negócios e traz consigo uma radiografia da saúde financeira/econômica, tecnológica e de desenvolvimento industrial do país.

Nas situações em que as taxas de exportações de bens e serviços estão inferiores às taxas de importações, existe a chamada déficit no saldo da balança comercial. Esse saldo negativo da balança comercial revela que se está vendendo menos bens e serviços para o exterior e importando mais. Esse é um cenário de preocupação porque pode resultar em prejuízo, uma vez que essa diferença deve ser coberta pelas reservas financeiras do país. Fazendo uma breve revisão histórica constata-se que durante parte da década de 90 o Brasil foi um país que tinha fronteiras relativamente fechadas às transações de importação (CARDINALE, 2019). Foi a parir de então que começaram a se desenhar políticas com o objetivo de suspender parte das barreiras não-tarifárias e foi definido um calendário de eliminação e redução de certas alíquotas de importação (condicionada também a entrada em vigor do Plano Real.

A eliminação das barreiras de importação tornou necessário investimentos em pesquisa, desenvolvimento e inovação tecnológica e o avançar nas políticas públicas que venham a favorecer estes investimentos que maximizem o desempenho exportador para as indústrias brasileiras, possibilitando maior inserção destas empresas no mercado internacional como também o aumento do volume exportado, o que vem contribuir diretamente no indicador de superávit da balança comercial (DE NEGRI; SALERNO; CASTRO, 2005).

\section{Indicadores de CT\&I}

Nas últimas décadas governos, organizações e instituições têm se preocupado em monitorar e avaliar processos, investimentos e resultados auferidos nesta incansável busca pela inovação. Indicadores foram concebidos para acompanhar a evolução, os impactos no crescimento econômico e no desempenho comercial das nações e também para diagnosticar gargalos e ações de melhorias nos processos, através do aprimoramento das políticas públicas, incremento do conhecimento e do investimento em ciência, pesquisa, desenvolvimento e inovação (SARTI; HIRATUKA, 2016; SCARPELLI; JUNIOR, 2013).

Pressupõe-se que existe ao menos um nível em que as entidades envolvidas no processo sejam qualitativamente similares, para que seja possível a realização de comparações em termos quantitativos (SMITH, 2006). Contribuições individuais de criação de indicadores de inovação foram identificadas já na década de 50 e em 1963, após encontro de especialistas da Organização para a Cooperação e 
Desenvolvimento Econômico (OCDE) com o grupo NESTI (National Experts on Science and Technology Indicators) em Frascati, Itália onde materializou-se a primeira edição do Manual de Frascati: Propose Standard Practice for Surveys of Research and Experimental Development (SCARPELLI; JUNIOR, 2013). Conforme Scarpelli; Junior (2013, p. 338) a iniciativa da OCDE foi de buscar uma padronização internacional dos métodos de coleta e divulgações dos resultados dos indicadores de inovação definidos como os principais na pesquisa do desenvolvimento econômico, quais sejam:

i) Dispêndios e pessoal aplicados em P\&D - grau do investimento aplicado diretamente a pesquisa e desenvolvimento;

ii) Balanço de pagamentos de transações de ativos intangíveis (Patentes) - circulação financeira e/ou econômica (transações) entre licenciados e detentores de ativos intangíveis (patentes, know-how, modelos e desenhos industriais, marcas e franquias, serviços técnicos e financiamento de P\&D industrial no exterior);

iii) Inovações tecnológicas de produtos e processos em empresas - tradução dos investimentos em inovação e seu impacto no reconhecimento empresarial e posicionamento da empresa e do país em rankings específicos;

iv) Evolução do número de depósitos e concessão de patentes - quantidade de depósitos e/ou concessão de patentes na autarquia responsável;

v) Recursos humanos engajados em atividades científicas e tecnológicas - quantidade de profissionais ligados diretamente em atividades científicas e tecnológicas.

Como o processo naturalmente evolui, a forma e os indicadores a serem considerados vem sendo rediscutidos. Hoje se considera além dos indicadores formatados pela OCDE, os indicadores bibliométricos, que medem quantitativamente a produção de pesquisa científica através do número de publicações e das citações. Para Torino; Vidotti; Sant'Ana (2019) a análise, coleta, processamento, armazenamento, disseminação, recuperação e acesso a dados científicos ou qualquer outro tipo de trabalho de impacto escrito é um importante veículo para disseminar e validar os resultados da pesquisa entre os pares, bem como o desenvolvimento da maturidade dos resultados científicos. Seguindo as recomendações de Cornell (2018), Litan; Wyckoff; Fealing (2014), Scarpelli; Junior (2013), Freeman; Soete (2009) a contagem de número de publicações e o número das respectivas citações são, portanto, uma fonte valiosa para medir o desempenho científico e acompanhar o desenvolvimento de novas tecnologias e da maturidade do conhecimento, contribuindo com as análises dos impactos dos investimentos em CT\&I na cadeia produtiva.

Dentro deste contexto, para o desenvolvimento do estudo proposto serão analisados os dados para cinco (05) indicadores a saber:

i) formação e alocação de pessoal para o desenvolvimento científico e tecnológico: importante indicador que caracteriza a evolução da formação de capacidades técnicas, de conhecimento e sua aplicação nas atividades científicas e tecnológicas, buscando fazer frente aos desafios demandados pela sociedade;

ii) produção de ativos intangíveis e seus impactos: indicador relevante que ajuda a aferir o potencial de geração de impactos inovadores é quantidade de publicações cientificas e o número de citações. Como resultado de grande relevância busca-se medir o impacto das publicações percebidas pela comunidade cientifica e sociedade.

iii) investimento em pesquisa e desenvolvimento: indicador que foca na análise do dispêndios realizados em projetos ou atividades que levem à produção de novos conhecimentos, aplicação do conhecimento existente e o consequente desenvolvimento tecnológico, ou seja as atividades científicas e tecnológicas e todos os ramos do conhecimento.

iv) evolução do número de depósitos de patentes um dos principais indicadores para se medir o potencial de tradução de investimentos em inovação. É um importante indicador inclusive para medir o potencial de geração de tecnologias pelos residentes de um país frente a 
concorrência do desenvolvimento tecnológico oriundo de outros países, além de possibilitar a identificação de rotas tecnológicas de desenvolvimento;

v) inovações tecnológicas de produtos e processos em empresas: maximizando os demais indicadores, este indicador busca avaliar de forma ampla todos os tipos de inovação alavancadas ou não por atividades de P\&D. Ou seja, busca-se medir e avaliar com este indicador o processo e a capacidade de uma empresa e do respectivo país quanto a tradução de suas políticas de fomento e dos investimentos diretos e indiretos em inovação, ou seja, a geração de impactos econômicos, financeiros e socioambientais.

A metodologia utilizada para análise e a correlação com a realidade da balança comercial é apresentada a seguir.

\section{Metodologia}

Nos termos de Gil (2002) e Creswell (2010) esse estudo se caracteriza como pesquisa de natureza qualitativa uma vez que a interpretação dos dados será de forma indutiva, com foco nos significados deles para entender a relação entre os indicies de inovação e a Balança Comercial. Terá um enfoque exploratório com o objetivo de levantar informações em diferentes bases de dados sobre os índices de inovação na última década no Brasil e no exterior. Esse levantamento deve auxiliar no alcance do objetivo geral do estudo. Nesse sentido, fez-se um esforço de levantamento de informações bibliográficas em artigos científicos, periódicos e publicações oficiais em documentos, bem como nos sites institucionais, pois estas trazem melhor junção de informações e veracidade ao resultado apresentado (MARCONI; LAKATOS, 2011). Para Neves (1996) este tipo de pesquisa qualitativa ocorre de forma dinâmica, mas com certo nível de complexidade e trabalho, entretanto, devido a interação contínua entre a coleta e o tratamento dos dados, permite ao pesquisador interpretar e analisar as informações coletadas com certo grau de precisão e aprendizado.

No processo de construção do referencial teórico e do plano de coleta de dados e construção do corpus da pesquisa, foi realizada análise documental de arquivos disponibilizados e pesquisas por dados secundários junto aos órgãos nacionais e internacionais de reconhecida reputação e expertise, como publicações nos sites das instituições e reportagens, apresentações expostas em reuniões internas, e documentos institucionais disponibilizados em sites.

Os dados foram extraídos de bases primárias, tais como Ministério da Economia, Industria, Comercio Exterior e Serviços (MDIC); Ministério da Ciência, Tecnologia, Inovações e Comunicações (MCTIC); Instituto Nacional de Propriedade Industrial (INPI); United Nations Conference On Trade And Development (UNCTAD) das Nações Unidas (ONU); The Organisation for Economic Co-operation and Development (OECD); e de fontes secundárias, como Centro de Gestão e Estudos Estratégicos (CGEE); Cornell University, INSEAD, World Intellectual Property Organization (WIPO); National Science Foundation (NSF); Institute For Statistics da Unesco (UIS) e Clarivate Analytics.

Buscando obter maior qualidade e fidelidade dos dados foram realizados procedimentos de triangulação e validação de dados (BAUER; GASKELL, 2002) diminuindo as chances de interpretações equivocadas dos dados obtidos. A técnica de triangulação permite cruzar fonte de dados, utilizando diversas fontes de informação com a leitura dos sites e documentos disponibilizados, além da possibilidade de os dados serem analisados por mais de um pesquisador (PAIVA; LEÃO; MELLO, 2011).

Para a análise será considerado o período entre 2008 e 2018, a fim de identificar o cenário do desenvolvimento tecnológico do país na última década e os impactos na balança comercial, produzindo um marco para futuras comparações dos dados e realizações das próximas políticas públicas. Em algumas situações específicas, podem ocorrer cortes temporais no intervalo estudado para reforçar a argumentação apresentada ou de forma não intencional, devido à falta da disponibilidade de dados. 
Acredita-se que os resultados apresentados se forem analisados de forma conjunta, podem dar indícios das transformações recentes, ajudando os gestores a traçarem iniciativas e planos futuros para o crescimento socioeconômico do país calçado no desenvolvimento tecnológico.

\section{Resultados e discussão}

\section{Indicador 1 - formação de pessoal para o desenvolvimento científico e tecnológico}

Primeiramente será analisado o quantitativo da formação de conhecimento nos programas de pósgraduação, linha em que ocorre os desenvolvimentos de novos conhecimentos tecnológico, seja conhecimento teórico como conhecimento aplicado. Resgata-se aqui os principais resultados do levantamento recente do Centro de Gestão e Estudos Estratégicos (CGEE) finalizado em 2016 que gerou o relatório Mestres e Doutores 2015 - Estudos da demografia da base técnico científica brasileira. Para a consecução do trabalho, o CGEE utilizou os dados da base Capes e da plataforma Sucupira mantidas respectivamente pela Coordenação de Aperfeiçoamento de Pessoal de Nível Superior (Capes) do Ministério da Educação (MEC) e também da base de dados formada pela Relação Anual de Informações Sociais (RAIS) do Ministério do Trabalho e Emprego (MTE).

No gráfico abaixo observa-se o quantitativo de programas de mestrado acadêmico e profissional. Importante registrar que os dados levantados naquele momento abrangeram o período de 1996 a 2014, no entanto, pode-se aferir a taxa de crescimento dos programas de parte do intervalo em estudo, 2008 a 2014.

Gráfico 1: Número de programas de mestrado acadêmico e profissional, Brasil, 1996-2014

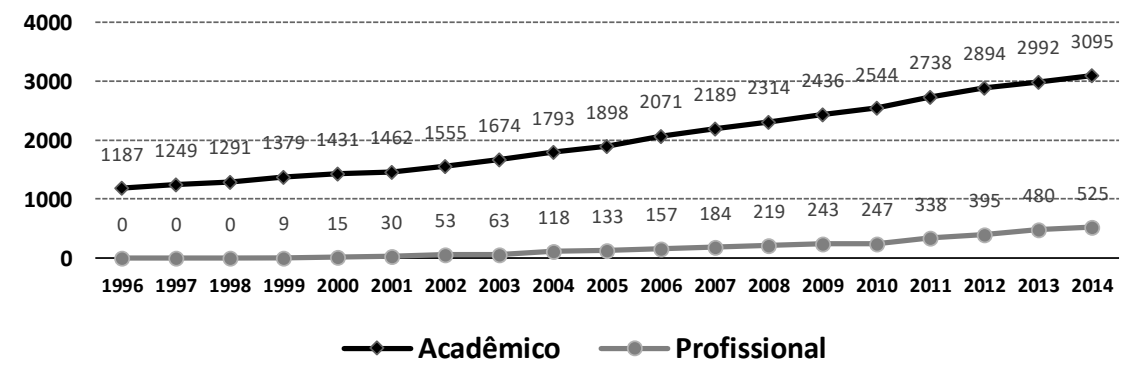

Fonte: Adaptado pelos autores de CGEE (2016)

Neste primeiro gráfico conclui-se que existe a predominância dos cursos de mestrado acadêmico, resultado natural, pois a criação do programa de mestrado profissional é relativamente recente, 1998, portaria $n^{\circ} 80$, de 16 de dezembro de 1998 (ABMES, 1998). Nota-se, porém, que as taxas de crescimento de ambas são diferentes. O mestrado acadêmico teve um crescimento médio de $5 \%$ no período de 2008 a 2014, já o do mestrado profissional a taxa média de crescimento foi de $16 \%$, três vezes mais, o que se pode explicar por ser uma modalidade recente no país e em expansão. Estes percentuais evidenciam a expansão dos programas de mestrado profissional que passaram de 219 para 525, um crescimento de $140 \%$, em contraponto, para o programa de mestrado acadêmico saiu de 2314 para 3095 , crescimento de $34 \%$, uma modalidade madura em nosso país.

Convém resgatar que um dos princípios norteadores da criação de mestrados e doutorados profissionais é agregar competitividade e produtividade as nossas empresas, públicas ou privadas, estreitando assim o relacionamento entre as universidades e o setor produtivo conforme as Portarias $n^{\circ} 131 / 2017$ e $n^{\circ}$ 389/2017 (DOU, 2017a, 2017b). Existe assim um elo com o amadurecimento do SNI, ou seja, ao buscar estreitar o acesso das empresas a formação de alto nível para seus profissionais, como mostra o estudo de Faccin; Bortolaso; Balestrin, (2016), eleva-se a qualidade dos resultados fabris, a geração de soluções 
e principalmente a busca pela inovação constante em processos e produtos (XIAO, 2020; KEKLIK, 2018; SCHUMPETER, 1984, 1997).

Esse indicador também resgata os efeitos práticos da articulação entre universidades, empresas e governo para o amadurecimento do SNI e o desenvolvimento econômico e social, a chamada Hélice Tríplice, conforme explorado por Etzkowitz; Zhou (2017) e inicialmente difundido por Leydesdorff; Etzkowitz (1996, 1998a, 1998b). Cabe ainda analisar a distribuição por área de formação e a absorção pelas empresas dos mestres e doutores formados pelos programas de pós-graduação profissionais, conforme o gráfico 2 .

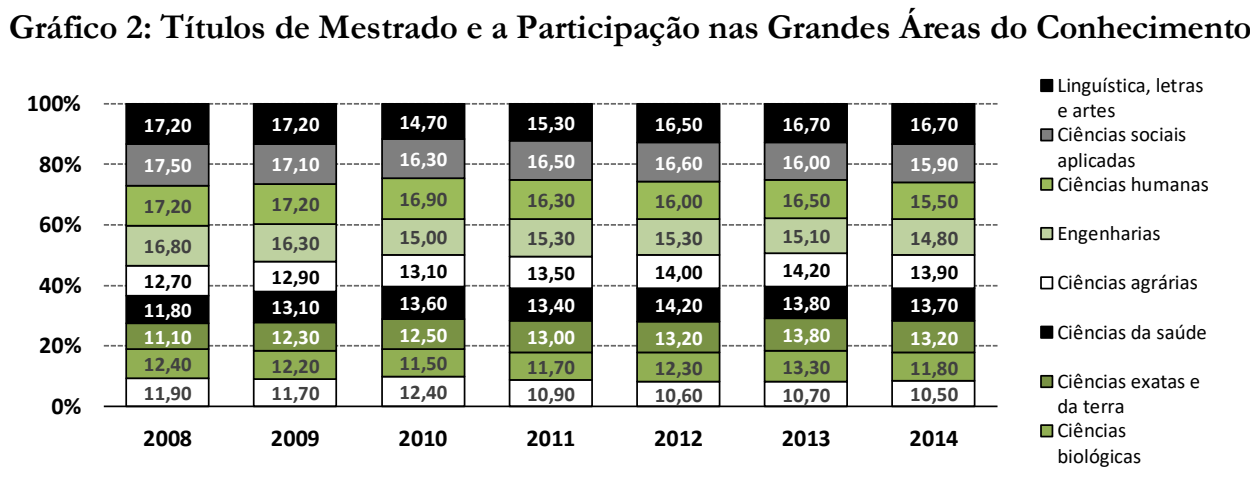

Fonte: Adaptado pelos autores de CGEE (2016)

Importante buscar o detalhe da distribuição do quantitativo das formações de mestre e doutores por área do conhecimento. Através dos dados disponibilizados em CGEE (2016), no intervalo de tempo de 2008 a 2014, verifica-se a prevalência dos programas de formação de mestres nas áreas de ciências de saúde $(15,69 \%)$, ciências humanas $(14,39 \%)$, ciências sócias aplicadas $(13,01 \%)$, ciências agrárias $(10,69 \%)$ e em áreas multidisciplinares $(14,59 \%)$ em comparação com as áreas das engenharias (10,58\%) e ciências exatas e da terra (8,18\%), percentuais alcançados em 2014. O que chama atenção é a área das engenharias, que para Mendes; Oliveira; Pinheiro (2013) são fundamentais na estruturação e sustentação do crescimento econômico, chegam a perder participação (a partir de 2010), remetendo para uma discussão acerca das opções estratégicas do Brasil para ter maior competitividade da pesquisa básica ao mercado, que impacta diretamente na balança comercial, em uma perspectiva global.

Com relação aos programas de doutorado verifica-se que da mesma forma que os programas de mestrado, é histórico a busca pela formação de doutores nas áreas de ciências de saúde (18,9\%), ciências humanas $(14,30 \%)$ e ciências agrárias $(12,5 \%)$ em comparação com as áreas das engenharias $(9,00 \%)$ e ciências exatas e da terra $(9,4 \%)$, percentuais alcançados em 2014. Visualiza-se também gradativa diminuição da participação percentual das engenharias e das ciências exatas e da terra no total dos programas. Esse dado se alinha com os achados de Cirani; Campanário; Silva, (2015) de que existe um desenvolvimento desigual entre as áreas, inclusive regionais, e um uma desidratação de áreas relevantes para a sociedade do conhecimento. Castilho (2017) articula essa diminuição do percentual das engenharias no total de programas com o fenômeno da desindustrialização que impacta negativamente sobre o crescimento econômico do país, uma vez que é a indústria que impulsiona a procura pelo conhecimento das universidades, fomenta a inovação e a melhoria da média salarial, gerando os maiores efeitos de alavancagem na economia e com o impacto que tanto se espera na balança comercial.

As vantagens estruturais da balança comercial favorável validam a preocupação de Costa (2020) para quem está em curso um processo de perda de competitividade das indústrias nacionais, principalmente em setores de tecnologia intensiva que são os maiores demandantes dos cursos das áreas das engenharias.

Como reflexo do número de programas de mestrado, as áreas de linguística, letras e artes, ciências sociais aplicadas e ciências humanas apresentaram destaque a participação de formações de mestres dentro do 
período analisado em comparação com as demais áreas. Em 2014 estas áreas alcançaram, respectivamente $16,7 \%, 15,9 \%, 15,5 \%$. Todavia, as áreas de engenhara e de ciências exatas e da terra não ficaram muito atrás, $14,8 \%$ e $13,2 \%$, em números de 2014 .

Com relação a formação de doutores o resultado foi parecido. Conforme dados do CGEE (2016), os programas de doutorado das áreas de ciências de saúde, ciências humanas e ciências agrárias conseguiram alcançar também uma maior participação na formação de doutores ao final de 2014, respectivamente $18,3 \%, 16,7 \%$ e $13,10 \%$. Infelizmente as áreas de engenharia e de ciências exatas e da terra não conseguiram alcançar o mesmo percentual de formação, 9,6\% e 9,7\% respectivamente. Convém destacar que os números em 1996 eram totalmente diferentes, conforme dados do CGEE (2016). As engenharias e ciências exatas e da terra possuíam posição de destaque na participação da formação de doutores no país (engenharias: 13,2\%; ciências exatas e da terra: 16,2\%), um sinal de que os cenários que se instalaram no país desfavoreceram estas áreas intensivas de conhecimento, além de apontar para o que Ramos (2018) denomina como falta de mecanismos institucionais nos órgãos de ensino superior que apontem estratégias administrativas para mudar esse cenário de fortes indícios de especialização regressiva. Para Maia (2020) esses indicadores têm relação direta com as demandas de trabalho no setor de serviços (educação, saúde, segurança, entretenimento etc.).

Um importante indicador que tem relação direta com o grau de desenvolvimento tecnológico do país é o nível de formação dos profissionais de nossas empresas, ou seja, deste quantitativo de mestres e doutores quantos foram absorvidos na cadeia produtiva industrial? Para responder esta pergunta o CGEE realizou o levantamento.

Tabela 1: Número de Mestres e Doutores Titulados no Brasil X Número de Mestres e Doutores Empregados em Empresas

\begin{tabular}{|c|c|c|c|c|}
\hline $\begin{array}{c}\text { Mestres e Doutores (empregados x } \\
\text { desempregados) }\end{array}$ & 2009 & 2014 & $\begin{array}{l}\text { Aumento do } \\
\text { emprego por ano }\end{array}$ & $\begin{array}{c}\text { Taxa média de } \\
\text { crescimento anual } \\
(\%)\end{array}$ \\
\hline Mestres (A) & 277.351 & 445.562 & 28.035 & $10,1 \%$ \\
\hline Empregados (B) & 184.960 & 293.381 & 18.070 & $9,8 \%$ \\
\hline Empregados em Empresas Estatais (C) & 11.175 & 17.407 & 1.039 & $9,3 \%$ \\
\hline Empregados em Empresas Privadas (D) & 39.906 & 63.783 & 3.980 & $10,0 \%$ \\
\hline Taxa de emprego formal (B/A) $(\%)$ & $66,7 \%$ & $65,8 \%$ &.. &.. \\
\hline Percentual de mestres nas empresas $(\mathrm{C}+\mathrm{D}) / \mathrm{B}$ & $27,6 \%$ & $27,7 \%$ &.. &.. \\
\hline Doutores (E) & 98.665 & 168.143 & 11.580 & $11,7 \%$ \\
\hline Empregados $(\mathrm{F})$ & 73.767 & 126.902 & 8.856 & $12,0 \%$ \\
\hline Empregados em Empresas Estatais $(\mathrm{G})$ & 2.715 & 4.306 & 265 & $9,8 \%$ \\
\hline Empregados em Empresas Privadas $(\mathrm{H})$ & 5.841 & 10.152 & 719 & $12,3 \%$ \\
\hline Taxa de emprego formal $(\mathrm{F} / \mathrm{E})(\%)$ & $74,8 \%$ & $75,5 \%$ &.. &.. \\
\hline Percentual de doutores nas empresas $(\mathrm{G}+\mathrm{H}) / \mathrm{F}$ & $11,6 \%$ & $11,4 \%$ &.. & .. \\
\hline
\end{tabular}

\section{Fonte: Adaptado pelos autores de CGEE (2016)}

Conforme tabela 1, do total dos 445.592 mestres formados no final de 2014, apenas 27,6\% (81.190) foram absorvidos pelas empresas públicas ou privadas. Com relação ao quantitativo de doutores, dos 168.143 formados e 126.902 atuando, apenas 11,4\% (14.458) foram absorvidos pelas empresas públicas ou privada, ou seja, esses dados corroboram Ferreira et al (2017) para quem existe uma política de formação de profissionais altamente qualificados, mas descasada das demandas da sociedade do conhecimento e dos setores produtivos. No total da força de trabalho são apenas $23 \%$ (95.648) de mestres e doutores atuando em empresas. A grande maioria dos profissionais formados (77\%), mestres e doutores estão na administração pública federal e estadual (governo, universidades etc.) Para Costa (2020) dado o panorama de uma política econômica que tem levado a desindustrialização do Brasil, a indústria possui somente o quarto maior salário real médio, conseguindo ficar atrás dos setores de extração mineral (commodities), serviços industriais de utilidade pública e administração pública, situação que reforça a falta de atratividade por estes profissionais à indústria intensiva. 
Correlacionando o número total de profissionais doutores e mestres atuando no setor empresarial (95.648) por atividade econômica (GALINDO; VERGER, 2016), conclui-se que apenas 16,9\% (16.134) estão na indústria de transformação, ou seja, aplicando tecnologia intensiva e ou desenvolvimento tecnológico. Refinando o resultado, com foco na indústria intensiva, a indústria de transformação avançada (aeronaves, farmacêutica e de informática, eletrônicos e produtos óticos), o número cai consideravelmente para 3,1\% dos 95.648 profissionais mestres e doutores absorvidos pelas empresas.

Fazendo um comparativo com os resultados da balança comercial destas atividades econômicas para o ano de 2014, tabela 2 abaixo, identificamos déficit de exportação da nossa indústria nacional de transformação principalmente na produção de tecnologias intensivas (alta, média-alta e média-baixa tecnologia $)^{1}$. Existem diversas variáveis que levam a este resultado, contudo, é relevante a necessidade de profissionais especialistas, com competências complexas, no corpo técnico de empresas, principalmente quando se trata de indústria intensivas e de desenvolvimento de novas tecnologias (CNI, 2016; FERREIRA, 2016).

Tabela 2: Balança Comercial Industria de Transformação (x R\$ 1.000.000)
\begin{tabular}{l|c} 
ATIVIDADE ECONÔMICA (DIVISÃO \\
OCDE)
\end{tabular}
\begin{tabular}{l|c} 
Alta Tecnologia & $\mathbf{2 0 1 4}$ \\
\hline Média-Alta Tecnologia & $-29.709,05$ \\
\hline Média-Baixa Tecnologia & $-56.607,10$ \\
\hline Baixa Tecnologia & $-12.970,79$ \\
\hline
\end{tabular}

Fonte: Produzido pelos autores através dos dados abertos do MDIC (2019)

O déficit de exportação se relaciona sistemicamente também com o baixo grau de abertura de certos setores ineficientes que estão a anos se beneficiando de subsídios fiscais (dando-lhes uma sobrevida) prejudicando os setores de atividade que tem demanda por mão de obra qualificada, o que aqueceria a busca por cursos nas áreas de exatas, engenharia e em competências tecnológicas, diagnóstico que corrobora com os estudos realizados pela Confederação Nacional da Industria em 2016 e 2017 (CNI, 2017, 2016).

\section{Indicador 2 - produção de ativos intangíveis e seus impactos}

Conforme Cornell (2018); Litan; Wyckoff; Fealing (2014); Scarpelli; Junior (2013); OECD (2012), outro indicador relevante para medir o potencial inovador é quantidade de publicações cientificas e o número de citações, ou seja, a relevância e ou impacto que aquela publicação acarretou a comunidade cientifica. Ou seja, a partir da imagem do quantitativo relevante de mestres e doutores formados em nosso país, pergunta-se: qual a colocação que o país se encontra quanto ao número de publicações realizadas dentro do período de estudo deste artigo e qual o percentual de impacto e as áreas de estudo destas publicações com relação as produções mundiais?

Do recente levantamento de Cross; Thonsom; Sinclair (2017), produzido a partir dos dados extraídos da Web of Science entre 2011 e 2016, o Brasil está na décima terceira (13a) colocação em termos de número de artigos revisados por pares produzidos no mundo, o que o coloca entre os países que mais publicam mundialmente. Segundo os resultados, a maioria dos trabalhos resultam de projetos de pesquisa e desenvolvimento e nos últimos 20 anos o percentual de publicação vem aumentando.

Entretanto, deve-se analisar o número e o resultado com parcimônia incluindo uma importante variável, o fator de impacto do artigo (RUIZ; GRECO; BRAILE, 2009), ou seja, bons artigos naturalmente citam artigos anteriores, refletindo assim sua contribuição intelectual ao estado da arte no assunto estudado. Conforme os dados disponibilizados pela Clarivate Analytics o impacto dos artigos brasileiros, em termo do número de citações, tem sido historicamente abaixo da média mundial, mas aumentou 18\% entre 2011 e 2016 (0,73 para 0,86). Convém destacar que, conforme Cross; Thonsom; Sinclair (2017), o termo 
"impacto de citação" é usado para se referir à média normalizada de contagem de citações para um artigo ou grupo de artigos, em vez da contagem de citações por artigo. Este procedimento é para corrigir tendências indesejadas provocadas por exemplo pela "idade", tempo de publicação, de um artigo (artigos mais antigos tiveram mais tempo para coletar citações do que os mais recentes).

No gráfico 3 mostra o comportamento do fator de impacto das citações dos artigos brasileiros (linha contínua), ficando abaixo da média mundial (linha pontilhada).

\section{Gráfico 3: Fator de Impacto de Citação dos Artigos Brasileiros}

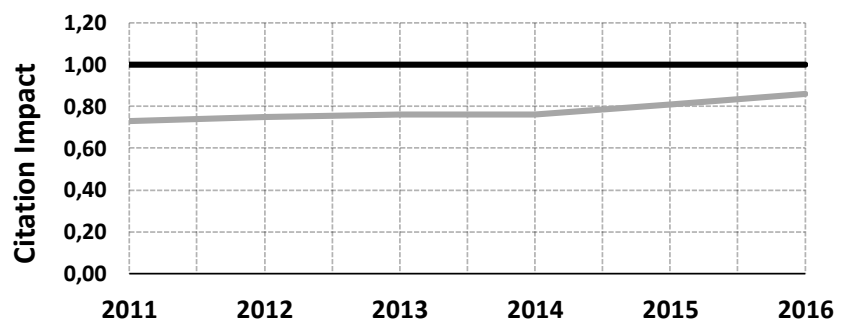

Fonte: Adaptado pelos autores através dos dados de Cross; Thonsom; Sinclair (2017)

Um importante diagnóstico registrado foi que, dos 250.680 artigos e resenhas publicadas por pesquisadores brasileiros entre 2011 e 2016, apenas 1\%, em média, tinha ao menos um autor ligado ao setor industrial, aproximadamente 2.500 artigos. O fato é que este número não se eleva e seu perfil é quase constante. Mergulhado nos dados, dentre as empresas da indústria de transformação, identifica-se que a Petrobras foi a principal empresa brasileira que publicou artigos em parceria com pesquisadores, 190 no total. Todavia, segundo Cross; Thonsom; Sinclair (2017) o fator de impacto das publicações ficou menor que as demais publicações do intervalo estudado, 1.04, no entanto, foi maior que a média mundial. É relevante registrar que a indústria farmacêutica foi a que teve a maior quantidade de artigos em parceria, 843, e o fator de impacto foi extremamente relevante, chegando a 30,37. Restou evidenciado que é necessário estabelecer critérios e estímulos setoriais para que as publicações nacionais sejam mais direcionadas a problemas concretos e setores estratégicos específicos, sejam elas da área da saúde, industrial, de tecnologias intensivas, segurança, nanotecnologias, defesa etc., atendendo sua missão de melhorar as condições de vida na sociedade.

Comparando o desempenho das publicações em relação aos países do BRICS (China, Índia, Rússia e África do Sul), com países vizinhos (México e Argentina) e países desenvolvidos como Alemanha, França, Canadá, Espanha e Japão, o Brasil ficou apenas a frente da Rússia, e atrás da Índia e da China. Registrase que o fator de impacto do Brasil foi o mesmo do que da Índia, 0,78, mesmo tendo 96.613 a menos de publicações, o que sugere um melhor fator de impacto final das publicações brasileiras em relação as indianas e, perde em fator de impacto para a África do Sul que, com apenas 73.663 alcançou 1,11 de impacto. Com relação aos países desenvolvidos, o Brasil de fato fica muito atrás tanto em quantidade como em fator de impacto, entretanto mantem folga em relação ao México e Argentina. Com relação a colaboração nas publicações do setor industrial, o Brasil também fica atrás, exceto perante a Índia e a Rússia. O caso da China em todos as comparações é um ponto fora da curva.

A diferença do Brasil em relação aos países mais avançados expressa também a capacidade do estado em realizar investimentos orientados a resultados e da forma de contratação desses serviços e/ou de compras de produtos tecnológicos. Para De Negri (2017) as bolsas de estudo ou subvenções a projetos de pesquisa, como modalidades de contratação de serviços de $\mathrm{P} \& \mathrm{D}$, não cobram retorno concreto ao contratante (o estado brasileiro), apenas a pesquisa em si, sem a cobrança de outros resultados que poderiam melhorar o fator de impacto. Esta orientação corrobora com a visão do CNI (2017), onde o Estado Brasileiro deveria maximizar o uso dos mecanismos de compras públicas e/ou de encomendas 
tecnológicas, desta forma incentivaria diretamente a construção de capacitação técnica, gerando desenvolvimento tecnológico e soluções ao mercado pela industrial nacional.

Outro ponto que merece destaque é: Quais áreas do conhecimento as publicações brasileiras se concentraram? Os resultados demonstraram a concentração nas áreas de Medicina (46,840), Ciência Natural (plantas e animais) (30.980), Ciências Agrícolas (25.629), Química (19.345), Física (15.040), Engenharia (12.092), Ciências Sociais (11.555), Biologia e Bioquímica (11.537), estas foram as primeiras do ranking com as respectivas quantidades. As publicações que ultrapassaram a média mundial para fator de impacto foi as da Física $(1,24)$ e de Ciência do Espaço $(1,37)$. Enquadrando estes resultados dentro das áreas de conhecimento que remetem as áreas intensivas em tecnologia da indústria de transformação, utilizando a classificação da OCDE (GALINDO; VERGER, 2016), destaca-se os impactos dos artigos brasileiros em nível de top five: Astronomia e Astrofísica - 1,59 (4.767 artigos); Física, Partículas e Campos - 1,52 (4.248 artigos); Física Multidisciplinar - 1,40 (3.472 artigos); Matemática - 1,01 (3.577 artigos); Odontologia, Cirurgia Oral e Medicina - 0,98 (7.134 artigos); Energia e Combustíveis - 0,91 (2.897 artigos); Química Analítica - 0,83 (4.141 artigos); Farmacologia e Farmácia - 0,81 (7.598 artigos).

Pode-se concluir que apesar do Brasil estar muito aquém dos demais países desenvolvidos citados e dos principais atores dos BRICS (China e Índia), e a baixa absorção de doutores e mestres pela indústria de transformação de tecnologia intensiva, algumas publicações realizadas entre 2011 e 2016 tem logrado êxito nas contribuições tecnológicas e de conhecimento em importantes áreas, incluindo algumas de ponta com a Astronomia, Astrofísica e Física, Partículas e Campos, com destaque aos que tiveram fator de impacto além da média mundial: a média mundial Física $(1,24)$ e de Ciência do Espaço $(1,37)$. Isso indica que os desafios de inovação da Industria Nacional precisam de políticas mais maduras, instrumentos mais sofisticados de estímulo e um sistema regulador mais avançado para aproveitar essa produção intelectual.

Claro que o tecido empresarial também precisa de mentes mais abertas a inovação e ao desenvolvimento tecnológico, como indicam Costa (2020) e CNI (2016), e isso deve ocorrer a despeito de certas políticas governamentais retomarem componentes do velho protecionismo e deixar as políticas de inovação em segundo plano. No entanto, novos estudos específicos devem ser realizados a fim de inferir com maiores detalhes dos efeitos causados pela capacitação profissional e produção científica na balança comercial correlacionando comparativamente com outros fatores como, a inserção da tecnologia na indústria, impacto na economia interna, cotação do dólar e situação da economia externa (BADRAN; BAYDOUN; HILLMAN, 2020, CASSANO et al., 2017). Porém, fica evidente ao longo de sec. XX que a capacitação e a produção de conhecimento tecnológico estão na base da noção Schumpeteriana de "destruição criativa" quando os novos produtos e serviços superam as anteriores, melhorando as fontes de lucratividade e competitividade. E os países que têm feito as melhores apostas nessa direção tem conseguido superar o Brasil nesses quesitos.

\section{Indicador 3 - investimento em pesquisa e desenvolvimento}

Conforme OECD (2008), outro indicador relevante para medir o potencial inovador é o quantitativo do investimento em P\&D que um país tem realizado, seja através de recursos públicos como de recursos privados. Através dos dados disponibilizados pela secretária executiva do Ministério de Ciência, Tecnologia, Inovações e Comunicações (MCTIC), pelo National Science Foundation (NSF), The Organisation for Economic Co-operation and Development (OECD), e pela Institute For Statistics (UIS) da UNESCO, configurou-se uma análise qualitativa. O intervalo obtido de dados compreende 2008 a 2016.

Dados abertos do MCTIC (2019) indicam que o investimento feito em P\&D no Brasil tem crescido a uma taxa média acumulada de $11 \%$ de 2008 a 2016, e comparando os valores totais aportados em 2008 com o de 2016 identifica-se o crescimento de 126\%. Em termos da divisão do investimento público e empresarial, em média são proporcionais. No período estudado o valor investido de natureza pública 
somou $\mathrm{R} \$ 275$ bilhões de reais e em contrapartida o investimento privado somou $\mathrm{R} \$ 242$ bilhões de reais, uma diferença de $\mathrm{R} \$ 32$ bilhões de reais. O gasto médio anual do setor público foi de $\mathrm{R} \$ 32,22$ bilhões de reais e em contrapartida o gasto médio anual do setor privado foi de $\mathrm{R} \$ 28,19$ bilhões de reais. Dentro deste período a variação média acumulada do investimento público e privado tiveram o mesmo percentual, $11 \%$.

No gráfico 4 identifica-se uma taxa média de crescimento acumulada de $2 \%$ de 2008 a 2016 do investimento total em P\&D nacional com relação ao PIB. Com relação a natureza dos gastos, o comportamento em média é parecido. Analisando os dados, percebe-se que quase se atinge a regra do 1 para 1, para cada real do dinheiro público, um real é colocado pelo setor privado. Obviamente, em 2012 e 2013 a realidade foi diferente, provavelmente ocasionada pela crise econômica, mas sugere-se pelos dados que, a partir de 2015 o investimento proporcional começava ensaiar sua retomada. O ano de 2016 merece destaque, pois ocorreu uma queda de $6 \%$ do valor investido em relação ao PIB em comparação com o ano de 2015, cessando um aumento acumulado médio de 6\% ao ano que começou em 2012. Segundo De Negri et al. (2020) existe uma queda nos principais indicadores agregados de inovação no país, cenário negativo agravado pela crise da Petrobras, maior investidora em P\&D no país, além da própria crise político-econômica que afetou diretamente os investimentos em inovação das empresas que tem resultado em prejuízos, demandando a formulação de políticas públicas mais eficientes para estimular a inovação.

\section{Gráfico 4: Percentual de Dispêndio Nacional em P\&D por Setor em Relação ao PIB}

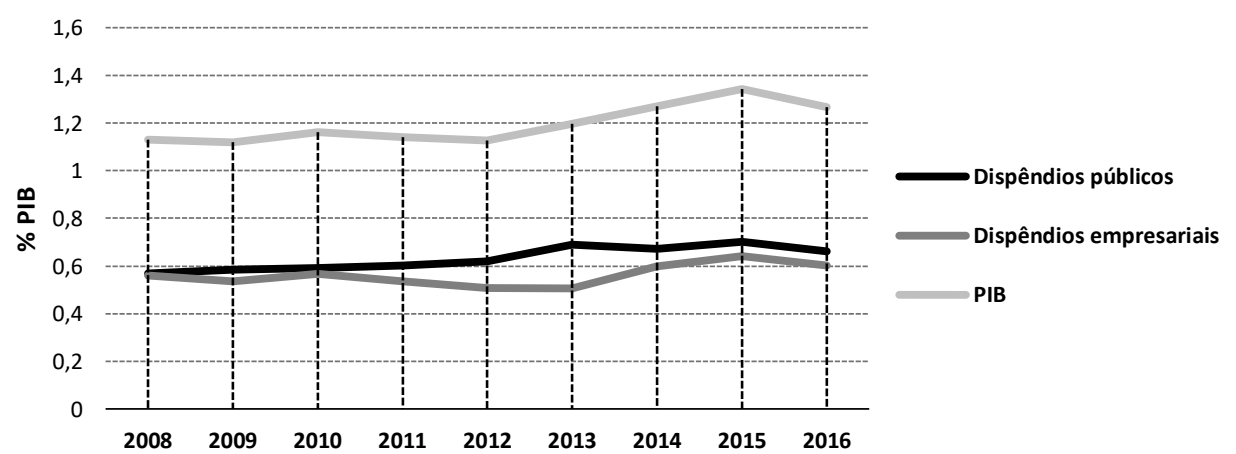

Fonte: Produzido pelos autores através dos dados abertos do MCTIC (2019)

Quando comparamos estes resultados com a dos Estados Unidos vemos que a situação é diferente. Em NSF (2017) observa-se que o crescimento médio anual acumulado americano foi de $2 \%$, quase uma constante, e comparando os valores totais aportados em 2008 com o de 2016 identifica-se o crescimento de $18 \%$. Contudo destaca-se a grande diferença no quantitativo do investimento entre o setor público e privado americano, o do setor público foi muito mais elevado. Somou a importância de 551 bilhões de US\$ e em contrapartida o setor privado alocou 228 bilhões de US\$, quase duas vezes e meia a menos. Com relação a variação média acumulada do investimento público e privado no período a diferença foi menor, 1\% e 4\% respectivamente (NSF, 2017). Conforme De Negri; Squeff (2014) as políticas de investimento em P\&D entre os EUA e o Brasil é calçado em profundas diferenças, o que gera estes números desproporcionais. A complexidade e a diversidade de instituições e as formas de atuação direta da política pública americana são alguns dos fatores.

Interessante também comparar o percentual do investimento em P\&D com relação ao PIB com os demais países do BRICS (China, Índia, Rússia e África do Sul), com países vizinhos (México e Argentina) e países desenvolvidos como Alemanha, França, Canadá, Espanha e Japão (tabela 3). 
Tabela 3: Percentual de Dispêndio P\&D em Relação ao PIB entre Países de Interesse

\begin{tabular}{l|c|c|c|c|c|c|c|c|c}
\hline \multicolumn{1}{c|}{ País } & $\mathbf{2 0 0 8}$ & $\mathbf{2 0 0 9}$ & $\mathbf{2 0 1 0}$ & $\mathbf{2 0 1 1}$ & $\mathbf{2 0 1 2}$ & $\mathbf{2 0 1 3}$ & $\mathbf{2 0 1 4}$ & $\mathbf{2 0 1 5}$ & $\mathbf{2 0 1 6}$ \\
\hline Japão & 3,34 & 3,23 & 3,14 & 3,24 & 3,21 & 3,31 & 3,4 & 3,28 & 3,14 \\
\hline Alemanha & 2,6 & 2,73 & 2,71 & 2,8 & 2,87 & 2,82 & 2,87 & 2,92 & 2,93 \\
\hline Estados Unidos & 2,77 & 2,82 & 2,74 & 2,77 & 2,69 & 2,72 & 2,73 & 2,74 & 2,74 \\
\hline França & 2,06 & 2,21 & 2,18 & 2,19 & 2,23 & 2,24 & 2,28 & 2,27 & 2,25 \\
\hline China & 1,44 & 1,66 & 1,71 & 1,78 & 1,91 & 1,99 & 2,02 & 2,06 & 2,11 \\
\hline Canadá & 1,86 & 1,92 & 1,83 & 1,79 & 1,78 & 1,71 & 1,72 & 1,65 & 1,6 \\
\hline Brasil & 1,13 & 1,12 & 1,16 & 1,14 & 1,13 & 1,2 & 1,27 & 1,34 & 1,27 \\
\hline Espanha & 1,32 & 1,35 & 1,35 & 1,33 & 1,29 & 1,27 & 1,24 & 1,22 & 1,19 \\
\hline Rússia & 0,97 & 1,16 & 1,05 & 1,01 & 1,03 & 1,03 & 1,07 & 1,1 & 1,1 \\
\hline África do Sul & 0,89 & 0,84 & 0,74 & 0,73 & 0,73 & 0,72 & 0,77 & 0,8 & 0,8 \\
\hline Índia & 0,79 & 0,84 & 0,82 & 0,77 & 0,76 & 0,74 & 0,71 & 0,69 & 0,8 \\
\hline Argentina & 0,47 & 0,59 & 0,56 & 0,57 & 0,64 & 0,62 & 0,59 & 0,62 & 0,53 \\
\hline México & 0,47 & 0,52 & 0,53 & 0,51 & 0,49 & 0,5 & 0,53 & 0,52 & 0,49 \\
\hline
\end{tabular}

Fonte: Produzido pelos autores através dos dados abertos do OECD (2019)

Observa-se que o Brasil está atrás da China, mas à frente da Rússia, Índia, África do Sul, Argentina e México. Realidade um pouco diferente do número de artigos publicados na Web of Science e do fator de impacto de citações mostrado no indicador 2 (Produção de ativos intangíveis e seus impactos), o que indica que, não se trata somente de elevar os investimentos em $\mathrm{P} \& \mathrm{D}$, mas também de dar foco estratégico nas áreas que são mais necessárias ao desenvolvimento sustentável da sociedade, gerando resultados e com impactos relevantes mundialmente. Já em relação a alguns países desenvolvidos, Estados Unidos, Alemanha, França, Canadá, Espanha e Japão, a situação é bem diferente, o Brasil fica muito distante, apenas próximo do investimento feito pela Espanha no período de 2014 e 2016. De fato, o valor empregado pelas nações desenvolvidas em P\&D é diferenciado, como atestam também os estudos de Badran; Baydoun; Hillman (2020) quando compara os investimentos da Europa e Estados com caminhos para inovação e empreendedorismo no mundo Árabe. A média do investimento gira em torno de 2,3 do PIB, com destaque aos valores empregados pelo Japão e Alemanha, média de 3\% e Estados Unidos com média de $2,74 \%$.

Interessante comparar estes resultados com os dados disponibilizados pelo Institute For Statistics da UNESCO UIS (2015). Os dados são do ano de 2015 e estão em milhões por PPP US\$, purchasing power parity, paridade do poder de compra, que permite comparar as quantias de país para país. Convém destacar que foi feito um recorte para abranger no gráfico 5 os países que historicamente são de interesse nacional de acompanhamento da evolução científica referenciada na literatura. O resultado é que o Brasil está em nono lugar, atrás apenas dos Estados Unidos, China, Japão, Alemanha, República da Coreia, França, Índia e Reino Unido, mantendo aderência aos dados levantados pela OECD (2019).

Outro ponto de reflexão em relação ao indicador 2 é que, mesmo com um expressivo valor de investimento em $\mathrm{P} \& \mathrm{D}$, o Brasil não consegue em termos percentuais atingir o mesmo fator de impacto em resultados acadêmicos (artigos) quando comparado aos demais países do BRICS e de longe quando comparado com os países desenvolvidos (CROSS; THONSOM; SINCLAIR, 2017).

Gráfico 5: Ranking Investimento em P\&D em Relação Milhões PPP US\$

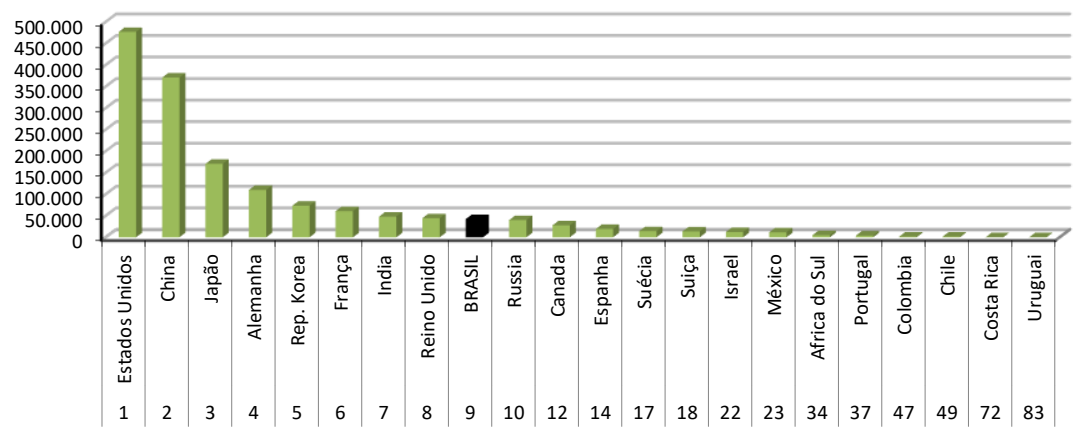

Fonte: Produzido pelos autores através dos dados abertos do UIS (2015) 
Esses dados corroboram com o estudo de Rocha et. al (2016), indicam que o Brasil tem índice de investimentos próximos dos países do primeiro mundo, no entanto os resultados práticos indicam que são países que tem níveis de eficiência diferentes. O Global Innovation Index (2018) também reitera esses resultados colocando o Brasil em último lugar entre os BRICS quando o assunto é eficiência em Inovação (CORNELL, 2018). Nesse sentido o Brasil ainda tem o desafio estratégico de estimular a cooperação em toda a cadeia de inovação que vai da bancada da universidade ao mercado, estimulando o intercâmbio entre universidades e empresas gerando inovações tecnológicas capazes de alavancar a balança comercial para além dos setores primários tradicionais.

Para Ramos (2018) e Mendes; Oliveira; Pinheiro (2013) esse esforço estratégico deve passar pela constituição de um ambiente político, econômico e legal favorável a parcerias estratégicas entre as universidades, institutos tecnológicos e empresas no processo de inovação, de modo a incrementar a competitividade das empresas no território nacional e internacional. Adicionalmente, por De Negri; Squeff (2014) corroborado por CNI $(2016,2017)$ o Brasil precisa de investimento direcionados a áreas estratégicas de desenvolvimento e engenharia, sempre buscando alavancar resultados concretos as demandas nacionais e, além da utilização do fomento via subvenção e por instituições públicas de pesquisa, é o uso da contratação direta de $\mathrm{P} \& \mathrm{D}$ e compras públicas de produtos tecnológicos a fim de atender as necessidades específicas.

O cenário atual de desenvolvimento capitalista é pautado pelo protagonismo do capital intelectual, e os países que tem mobilizado a produção intensiva de conhecimento e colocado em prática a criatividade e inovação em seus produtos e serviços acabam reafirmando os entendimentos de Lastres (2017) e Arocena, Göransson; Sutz (2017) para quem a competitividade econômica de países subdesenvolvidos está atrelada a capacidade do sistema nacional de inovação em beneficiar o sistema produtivo com mais conhecimento e tecnologia, de agregar valor à cadeia produtiva e a infraestrutura que servirá de base para a atuação das empresas que irão construir seus processos de produção, inovação e competitividade.

\section{Indicador 4 - evolução do número de depósitos de patentes}

Em maio de 2018 o INPI fechou seu relatório anual com os dados de depósitos e concessões ocorridas durante o ano de 2017, consolidando sua base de dados histórica. De fato, é relevante a análise deste indicador a fim de agregar conteúdo e conhecimento sobre a corrida tecnológica e seus impactos na cadeia produtiva e econômica do país, possibilitando reflexão e direcionamentos às políticas públicas para alavancar o desenvolvimento da indústria nacional. Período de dados disponibilizados foi de 2008 a 2017.

Analisando os dados disponibilizados por INPI (2019) destaca-se a notória desvantagem tecnológica que o país está enfrentando em número de depósitos. A grande maioria são de não residentes que em média depositaram ao ano 22.735 patentes. Os residentes apenas depositaram em média 4.718, uma diferença de 18 mil depósitos de patentes em média por ano. Dentro do período em estudo, 2008 a 2017, o total de depósitos nacionais somaram 47.189 e de não residentes 227.353 , o que representa $17 \%$ de depósitos de residentes e $83 \%$ de não residentes.

$\mathrm{Na}$ tabela abaixo apresenta-se o ranking de países depositantes no Brasil (INPI, 2019). Destaca-se que os depósitos dos residentes deixam o Brasil na segunda colocação. A hegemonia dos Estados Unidos no desenvolvimento de tecnologia também se demonstra em nosso território, com 31,4\% de todos os depósitos protocolados no INPI de 2000 a 2017 (419.327). Os depósitos nacionais responderam com $18,4 \%$ deste total, mas devemos nos questionar se de fato são de CPFs e de CNPJs de empresas de origem nacional. Curiosamente a China está na décima segunda colocação e sua representação no total de depósitos de 2000 a 2017 é de apenas 1,3\%. Os números materializam a realidade da busca pela soberania tecnológica como política de desenvolvimento nacional pelos Estados Unidos e demais países desenvolvidos, expandindo seus negócios no Brasil. Mesmo o Brasil sendo uma país que ao longo de décadas busca estreitar parcerias econômicas com os americanos (BRASIL, 2020), a sociedade americana 
entende que, em se tratando de desenvolvimento tecnológico e de conhecimento de ponta, é necessário buscar proteger mercado através de patentes, proporcionando retorno do investimento e ganhos econômicos (QUINTELLA; TEODORO, 2013).

Tabela 4: Número de Depósitos de Patentes por País de Origem

\begin{tabular}{|c|c|c|c|c|c|c|c|c|c|c|c|c|c|}
\hline \multirow{2}{*}{\multicolumn{2}{|c|}{ País }} & \multicolumn{10}{|c|}{ Ano } & \multirow{2}{*}{$\begin{array}{c}\text { Total } \\
2000 \mathrm{a} \\
2017 \\
\end{array}$} & \multirow[b]{2}{*}{$\%$} \\
\hline & & 2008 & 2009 & 2010 & 2011 & 2012 & 2013 & 2014 & 2015 & 2016 & 2017 & & \\
\hline 1 & Estados Unidos & 6980 & 6862 & 7561 & 8235 & 8680 & 9072 & 9617 & 10267 & 9100 & 7949 & 131707 & $31,41 \%$ \\
\hline 2 & Brasil & 4268 & 4262 & 4225 & 4705 & 4798 & 4955 & 4657 & 4640 & 5199 & 5480 & 77381 & $18,45 \%$ \\
\hline 3 & Alemanha & 2438 & 2132 & 2478 & 2825 & 3061 & 3006 & 2782 & 2500 & 2219 & 1910 & 41030 & $9,78 \%$ \\
\hline 4 & Japão & 1225 & 1476 & 1925 & 2611 & 2673 & 2702 & 2229 & 2143 & 1829 & 1717 & 26903 & $6,42 \%$ \\
\hline 5 & França & 1336 & 1420 & 1674 & 1786 & 2054 & 1784 & 1810 & 1709 & 1452 & 1355 & 24446 & $5,83 \%$ \\
\hline 6 & Suíça & 1287 & 1154 & 1217 & 1254 & 1355 & 1604 & 1408 & 1368 & 1347 & 1066 & 19175 & $4,57 \%$ \\
\hline 7 & Holanda & 789 & 738 & 842 & 1148 & 1112 & 1275 & 1412 & 1259 & 965 & 854 & 14891 & $3,55 \%$ \\
\hline 8 & Reino Unido & 592 & 558 & 667 & 824 & 791 & 728 & 808 & 730 & 697 & 657 & 10777 & $2,57 \%$ \\
\hline 9 & Itália & 579 & 502 & 579 & 627 & 724 & 771 & 703 & 695 & 640 & 601 & 9848 & $2,35 \%$ \\
\hline 10 & Suécia & 640 & 494 & 510 & 513 & 549 & 559 & 617 & 641 & 604 & 458 & 8880 & $2,12 \%$ \\
\hline 11 & República da Coréia (Sul) & 339 & 333 & 252 & 286 & 385 & 465 & 430 & 432 & 290 & 233 & 5514 & $1,31 \%$ \\
\hline 12 & China & 121 & 182 & 233 & 550 & 696 & 493 & 559 & 737 & 799 & 676 & 5465 & $1,30 \%$ \\
\hline
\end{tabular}

Fonte: Produzido pelos autores através dos dados INPI (2019)

Com relação aos depósitos nas áreas intensivas em tecnologia da indústria de transformação, aplicando um filtro nos dados brutos fornecidos pelo INPI (2019) para buscar somente depósitos que estariam atreladas as áreas intensivas em tecnologia da indústria de transformação, utilizando a classificação da OCDE (GALINDO; VERGER, 2016), apresenta-se abaixo gráfico 6 e a respectiva análise qualitativa.

\section{Gráfico 6: Número de Depósitos de Patentes Residentes e Não Residentes em Tecnologia da Indústria de Transformação}

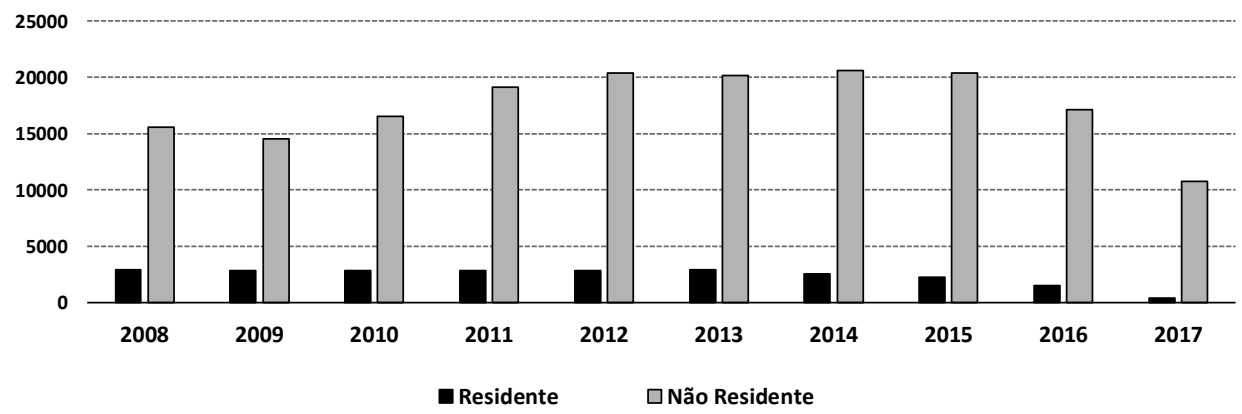

Fonte: Produzido pelos autores através dos dados abertos do INPI (2019)

Os números direcionam a uma reflexão e estão carregados de uma crescente preocupação. Primeiramente, desde 2014 que o quantitativo de depósitos de patentes dos residentes, que buscam desenvolver as áreas intensivas em tecnologia da indústria de transformação, tem sofrido declínio gradativo. Um declínio médio acumulado de 33\% (2014 a 2017). Destaca-se a abrupta queda de 2016 a 2017, 73\%. No mesmo período, também ocorreu declínio dos depósitos dos não residentes, todavia em percentual médio acumulado menor, $13 \%$. Os depósitos dos não residentes também tiveram queda abrupta de 2016 a 2017, de 37\%.

Deste último gráfico, identifica-se também a hegemonia dos não residentes em entrada de depósitos de patentes em nosso país. Do total de depósitos que alavancam tecnologias para a indústria de transformação entre 2008 e 2017, que representou 199.294, 88\% são de depósitos de não residentes (175.224). Os residentes representam apenas 12\% com um total de 24.070 depósitos de patentes. Demonstra-se o elevado interesse internacional, das suas empresas e centros de pesquisa, em proteger no nosso território o desenvolvimento tecnológico ligado as atividades econômicas da indústria de transformação. Releva-se da mesma forma que os números gerais da tabela 4, a importância que é 
atribuído ao mercado brasileiro pelos países estrangeiros e a fragilidade da indústria intensiva nacional. Conforme a Convenção da União de Paris (CUP) de 1883, a validade de uma patente é territorial, por isso a propriedade industrial assume no mundo capitalista moderno posição estratégica e de alta relevância pelo seu valor e potencial de negócio (BARBOSA, 2017b). Seu valor vem crescendo de forma acelerada e em algumas indústrias, é um dos principais ativos, da mesma forma que a terra no regime feudal (BUAINAIN; BONACELLI; MENDES, 2015).

Para Barbosa (2017a) a proteção da tecnologia via patente é uma técnica prevista em lei e em tratados internacionais de manipulação da concorrência, pois restringe legalmente a prática da concorrência em favor do detentor da patente, ou seja, fica evidenciado que os depositantes não residentes buscam delimitar o mercado e proteger sua tecnologia, seja para futuros negócios ou sua ampliação (como a compra de empresas e seus ativos intangíveis), garantir novos desenvolvimentos tecnológicos e principalmente, buscar a fidelidade de compra do produto patenteado pelos consumidores do país que ocorreu o deposito (BARBOSA, 2017a; GIRARD, 2012). Restou mais uma vez evidenciado, agora em números de patentes de origem nacional, que nossa indústria de transformação intensiva tem perdido espaço também em desenvolvimento tecnológico, afetando consequentemente o consumo interno de produtos com tecnologia nacional e a possibilidade de exportações em comparação a concorrência internacional. Esses dados também acompanham o histórico de desindustrialização diagnosticado na indústria nacional, em comparação a outros países concorrentes diretos do Brasil que tem indústria de transformação. O esforço do Brasil tem sido desenvolver e se integrar nas cadeias produtivas globais via instalação de grandes multinacionais que aportam tecnologia no nosso território justificando esta política como a forma mais rápida de informatizar e evoluir tecnologicamente o país. As consequências mais visíveis dessa política tem sido o crescimento do volume de capital estrangeiro sem a contrapartida da inserção comercial brasileira no estrangeiro (exportação), resultando na perda de competitividade das nossas empresas, e a desindustrialização com reflexo direto na balança comercial.

\section{Indicador 5 - inovações tecnológicas de produtos e processos em empresas}

Talvez o mais importante dos indicadores da lista da OCDE (2008) tenha sido o que mede se as inovações tecnológicas em produtos e processos de fato aconteceram e se estão gerando valor sustentável aos empresários e a sociedade conforme defendem Cornell (2018), Litan; Wyckoff; Fealing (2014), Scarpelli; Junior (2013), OECD (2012), Freeman, Soete (2009), Lundvall (1988, 1992, 2007), Edquist (1997, 2001), Schumpeter (1984, 1997), Nelson (1993) e Freeman (1982, 1987, 1988).

Para analisar o quanto o Brasil tem inovado e sua posição com relação aos demais países, iremos utilizar os dados e o levantamento realizado por Universidade de Cornell em parceria com o Instituto Europeu de Administração de Empresas (Insead) e a Organização Mundial da Propriedade Intelectual (OMPI). A parceria, de longa data, lançou em 2018 o décimo relatório da série, o Global Innovation Index (GII) (CORNELL, 2018). Importante destacar que neste relatório a Universidade de Cornell contou com a participação efetiva do Brasil através da Confederação Nacional da Indústria do Brasil (CNI) e o Serviço Brasileiro de Apoio às Micro e Pequenas Empresas (Sebrae).

Segundo Cornell (2018) o GII se alicerça em dois índices fundamentais: Insumos para Inovação e as Resultados da Inovação. O Início da Inovação se divide em 5 pilares (Instituições; Capital humano e pesquisa; Infraestrutura; Sofisticação de mercado e Sofisticação de negócios) que buscam coletar dados e informações de elementos da economia nacional e em 2 Pilares que capturam evidências reais de produtos de inovação (Produtos de conhecimento e tecnologia; Produtos criativos). Cada um destes 7 pilares é composto por oitenta indicadores individuais. A pontuação final é calculada por médias sucessivas após a coleta de cada um dos resultados (CORNELL, 2018).

O resultado apresentado no relatório da Cornell (2018) não é animador. O Brasil ficou na sexagésima quarta colocação $\left(64^{\circ}\right)$, atrás de todos os países do BRICS (China, Índia, Rússia e África do Sul), dos 
países desenvolvidos de referência como Estados Unidos, Alemanha, França, Canadá, Espanha e Japão, e do México. Neste indicador o Brasil ficou apenas na frente da Argentina que ocupou o octogésimo lugar. Pelos resultados obtidos dos indicadores anteriores, o resultado do GII é um vetor consequência, que retrata a realidade que se delonga a algum tempo e que as políticas públicas e ações historicamente criadas e implementadas nos diversos governos vem tentando mudar.

Correlacionando a análise deste resultado com os indicadores anteriores, fortalece e adensa os estudos de De Negri (2017), Arbix (2017), Turchi; Arcuri (2017) e De Negri et. al (2020) de que, não é só com o aumento do investimento em P\&D que o Brasil irá alavancar impacto aos temas contundentes demandados atualmente pela sociedade moderna que apela pelo crescimento sustentável. É necessário ter um projeto de Estado e atrelado a ele, um programa de governo, que direcionem o investimento de P\&D em áreas estratégicas demandantes de tecnologia intensiva de conhecimento possibilitando: formação profissional e sua absorção pelas empresas, geração de artigos com grau de impacto reconhecido pelos pares, e que naturalmente antes da publicação, os respectivos pedidos/registros da propriedade intelectual pelos residentes e fortalecimento dos elos do sistema nacional de inovação, formando assim o caminho sólido do processo inovativo, reconduzindo a uma retomada do mercado interno e a busca pelo externo da indústria nacional de transformação de tecnologia intensiva.

Uma forma simples de enxergar a relevância de se favorecer investimentos em P\&D para maximizar o desempenho exportador para as indústrias brasileiras é, por exemplo, a partir do estudo de Gallotti et al. (2017) . Os autores resgatam o paradoxo do mercado de café no Brasil. O Brasil tem a proeza de ser, simultaneamente, o maior produtor mundial (1/3 da produção mundial), o maior exportador mundial (30\% das exportações mundiais que são equivalentes a $\mathrm{R} \$ 21$ bilhões, em valor de 2015) e o segundo maior mercado consumidor de café. No entanto, a balança comercial do café está negativa. A razão disso é que o país, nos últimos anos, vem importando café com tecnologia que agrega maior valor ao produto (capsulas de café) e exporta matéria-prima bruta com baixo valor, a despeito dos investimentos feitos para melhor a qualidade do café nacional. O café solúvel é dos poucos produtos industrializados do café. E mesmo sendo um grande exportador de café solúvel a participação relativa do Brasil nesse nicho de mercado é decrescente," com uma exportação estacionada em 3 a 3,6 milhões de sacas por ano enquanto o consumo mundial desse formato aumenta" (GALLOTTI et al., 2017. p.2). Esse cenário ratifica a ideia de se desenvolver políticas estratégicas que estimulem maior inserção destas empresas no mercado internacional como também o aumentem do volume exportado, o que vem contribuir diretamente no indicador de superávit da balança comercial.

\section{O diagnóstico dos impactos na balança comercial}

Após o diagnóstico apresentado nos cinco indicadores, converge-se a análise dos impactos na balança comercial brasileira no período em estudo (2008 a 2018). Como um dos indicadores principais para analisar a competitividade de um país, o estudo dos dados da balança comercial é fundamental para tomada de decisões e alinhamento das políticas públicas de CT\&I. Segundo os dados brutos analisados do MDIC (2019), a balança comercial brasileira apresentou em 2018 um superávit de 58,65 bilhões de US\$, um recuo de 12,4\% com relação a 2017 onde o resultado alcançou 66,98 bilhões de US\$. Entretanto é importante relembrar que no período de 2008 a 2015 os resultados foram muito piores, sendo o pior o de 2014, déficit de 4,15 bilhões US\$.

Abaixo apresenta-se o gráfico 7 de exportação de produtos da indústria de transformação por intensidade tecnológica, utilizando a classificação da OCDE (GALINDO; VERGER, 2016), e demais produtos não classificados quanto a intensidade tecnológica (N.C.I.T). Os resultados revelam e materializam a realidade apresentada pelos resultados de Cornell (2018) e sugere o reflexo dos resultados dos demais indicadores estudados. Revelam a predominância da exportação de commodities e de produtos de baixo valor agregado. Dos dados brutos coletados, identifica-se alguns pontos de certa relevância: em 2017 e 2018 ocorreu um leve aumento das exportações (média acumulada de $2 \%$ ) de produtos de alta tecnologia. Entretanto no 
mesmo período o crescimento das exportações de commodities e de produtos de baixo valor agregado foi muito superior (média acumulada de $28 \%$ ). No mesmo período, as importações de comodities e de produtos de baixo valor agregado foram três (3) vezes menor que as respectivas exportações, mas em contraponto as importações de produtos da indústria de transformação de alta e média alta tecnologia representaram, respectivamente, 3,5 a 2,0 vezes a mais do que as exportações, revelando acentuada dependência internacional de produtos intensivos em tecnologia.

Gráfico 7: Exportação da Industria de Transformação e outros produtos N.C.I.T

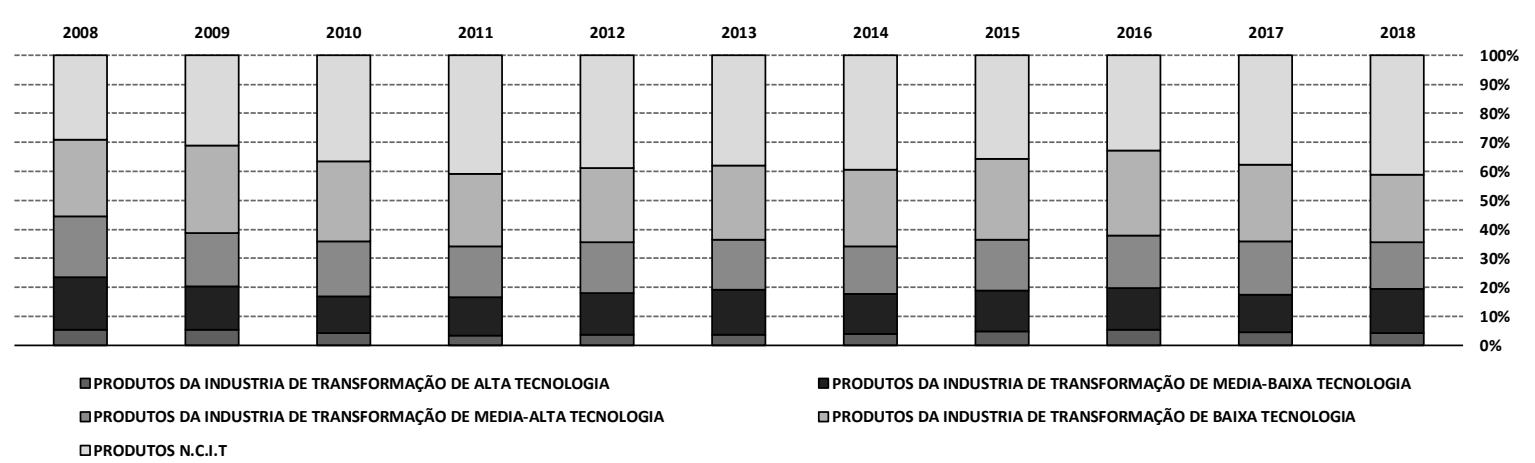

Fonte: Produzido pelos autores através dos dados abertos do MDIC (2019)

Constata-se o déficit tecnológico (balança comercial da indústria de transformação de produtos de intensidade tecnológica), ou seja, nossa economia de longa data gira atrelada fundamentalmente nas exportações de commodities e de produtos de baixo valor agregado. O saldo negativo da balança comercial da indústria de transformação de alta tecnologia já ultrapassa os 10 anos, chegando aos impressionantes US $\$-257$ bilhões (FOB) acumulados. Da mesma forma para a indústria de transformação de média-alta tecnologia US\$ -434 bilhões (FOB) e da média-baixa tecnologia US\$ -44 bilhões (FOB).

Aplicando uma lupa nos dados, no gráfico 8 podemos aferir que apenas a indústria de aeronaves se sobressai na balança comercial de produtos de alta e média alta tecnologia no período estudado (2008 a 2018). Em 2018 a indústria de aeronaves e toda a cadeia produtiva e de fornecedores ligados diretamente e indiretamente aos seus componentes fecharam balança comercial positiva de US \$ 5,7 bilhões (FOB) . Este resultado se fortalece e se relaciona com a maturidade do desenvolvimento tecnológico e da pesquisa científica demonstrado no indicador 2 estudado anteriormente: número de publicações cientificas e o nível de impacto destas na comunidade científica nas áreas de conhecimento que tem correlação com esta indústria: Astronomia e Astrofísica - grau de impacto 1,59 (4.767 artigos); Física, Partículas e Campos - grau de impacto 1,52 (4.248 artigos) e Física Multidisciplinar - grau de impacto 1,40 (3.472 artigos). Este diagnóstico adensa e atualiza os estudos de ABPI (2015) e ABPI; IPEA (2014) revelando e traduzindo em números positivos da balança comercial brasileira proporcionado por esta indústria, puxado pela Embraer e toda a engenharia e cadeia produtiva aeronáutica do país. O estudo revela o marco que este setor industrial proporcionou ao país, a entrada de divisas e a demanda pela mão de obra altamente especializada. Resta saber o que o futuro nos reserva, se o estado mantem como opção estratégica a manutenção e fortalecimento das cadeias produtivas nacionais que tem potencializado os ganhos da indústria aeronáutica tupiniquim, ao mesmo tempo que fornece as bases para o superar o nosso subdesenvolvimento e as desigualdades sociais e econômicas presentes na sociedade brasileira. 


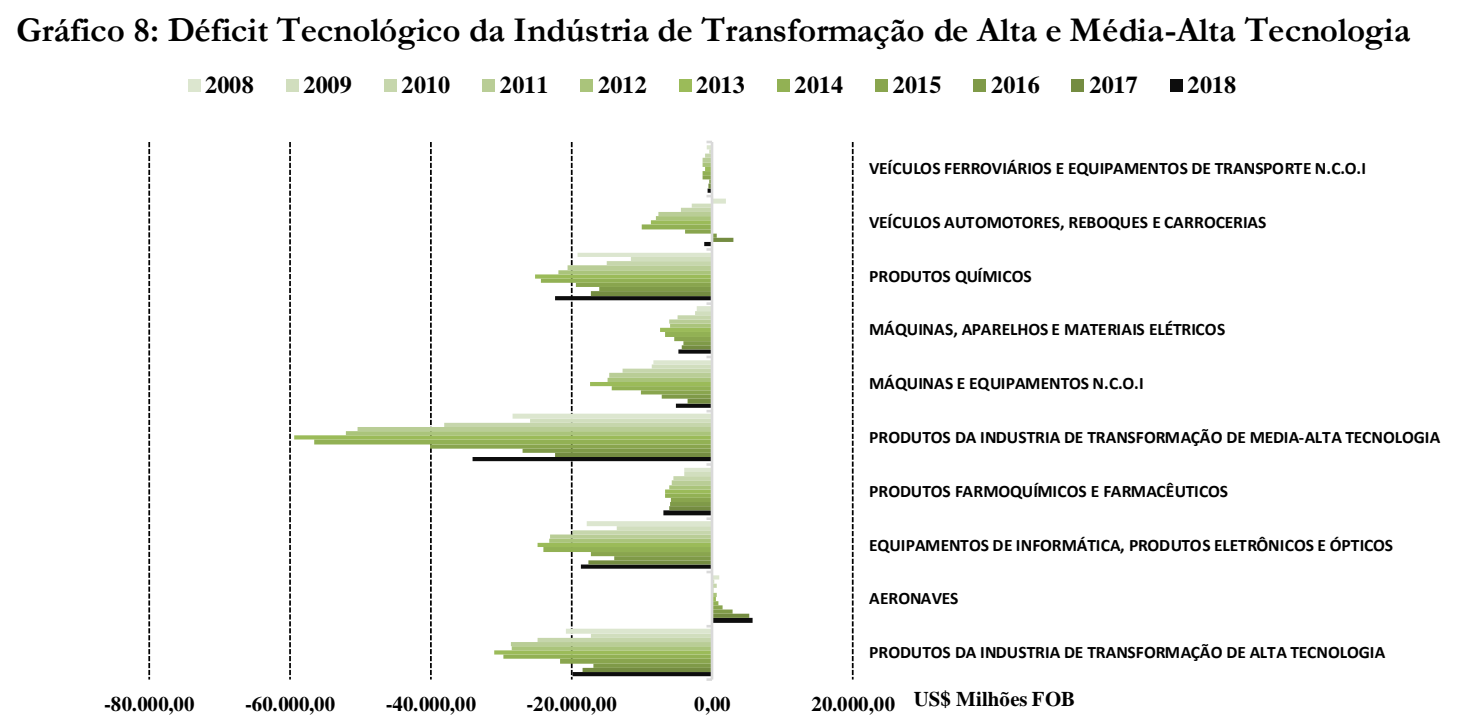

Fonte: Produzido pelos autores através dos dados abertos do MDIC (2019)

Afere-se a soma do déficit tecnológico das indústrias de alta e de média-alta tecnologia pela média acumulada de déficit da balança comercial das indústrias de alta e de média-alta no período de 2008 a 2018 foi de US\$ -62.852,20 milhões (FOB). A resultante sugere que o Brasil, historicamente, sofre um processo grave de desindustrialização na maioria dos setores de alta e média-alta tecnologia (a exceção a de aeronaves). Voltando ao resultado geral da balança comercial brasileira, que nos últimos anos (incluindo 2018), apresentou superávit, os dados brutos revelam que este resultado foi alavancado quase que exclusivamente pela exportação das commodities e dos produtos de baixo valor agregado. Durante o estudo também ficou claro que o comportamento da balança comercial também foi afetado pelos preços das commodities estipulado pelo mercado externo. Dados da UNCTAD (2019) indicam que entre 2017 e 2018 os preços das commodities sofreram 17\% e 16\% de aumento respectivamente.

A análise cruzada indica forte indício da desindustrialização da economia nacional, demonstrado por décadas de déficit tecnológico, provocado pelas respectivas políticas de governo adotados nas últimas décadas, adensando o estudo de Esposito (2017) e Maia (2020) e para quem esses indícios se revelam na ausência de um projeto de industrialização minimamente condizente com eixos dinâmicos do contexto atual do capitalismo, na desarticulação do sistema industrial, no deslocamento do eixo dinâmico da economia para o exterior e na erosão dos centros internos de decisão.

Os programas e políticas de CT\&I de governo não conseguiram ou não objetivaram de fato destravar decididamente o desenvolvimento tecnológico com foco no investimento direto em temas estratégicos ligados à indústria intensiva de transformação tecnologia e de conhecimento, que alavancaria a produção de bens intangíveis (propriedade industrial) e tangíveis de alta relevância de mercado, à produção científica de alto impacto, o fortalecimento dos elos do sistema nacional de inovação, formação especializada de profissionais e consequentemente a geração de empregos duradores, que ajudaria a tirar o país da realidade severa que o acomete nos últimos anos. Os estudos que balizam esse debate a partir da tríade juros elevados, câmbio sobrevalorizado e redução de tarifas de importação também reconhecem a desindustrialização do país e a superespecialização da produção no setor da agroindústria e da extração mineral.

Essa constatação é importante porque fornece bases sólidas que validam os diagnósticos aqui realizados e reforça a necessidade de provocarmos os ciclos Schumpeterianos de "destruição criativa" e cumprir a missão de constante busca pela criação de algo novo que indubitavelmente destrói as velhas regras e estabelece outras novas potencializadoras de maior prosperidade econômica 


\section{Conclusão}

A proposta dessa pesquisa foi a de analisar se a competitividade nacional no mercado externo foi minimamente alavancada pelas políticas públicas adotadas na última década (2008-2018). Para isso cruzamos informações a respeito dos indicadores de CT\&I e os resultados da balança comercial brasileira no período. Levantamos informações a respeito de indicadores de desenvolvimento do conhecimento, produção científico-tecnológica, investimento em $\mathrm{P} \& \mathrm{D}$, propriedade industrial e do índice de inovação do Brasil em relação aos demais países do BRICS, alguns países vizinhos e de alguns países desenvolvidos que o Brasil tem estreita relação comercial.

Os dados indicam que o país precisa avançar muito em políticas e ações de inovação para de fato colocar em prática os ensinamentos de Schumpeter (1997) desde 1934 e dos demais formadores de políticas de desenvolvimento como Cassiolato e Lastres (2017), Barbosa (2017a), Keklik (2018), Edquist (2019), Etzkowitz, Zhou (2017), Freeman (2019), Arbix (2020), Buainain (2020), Costa (2020), De Negri (2020), Hiratuka Esarti (2020), Quintella e Teodoro (2020). O Brasil tem um longo caminho a percorrer para um desenvolvimento maduro no campo da inovação que renove o seu potencial de crescimento e tenha reflexos duradores na economia nacional.

O Brasil sente o reflexo desta realidade quando ao final do ano fecha-se a balança comercial. Historicamente o país está sujeito as exportações de commodities e aos preços ditados por quem compra do outro lado. Como consequência o país se submete a uma dependência tecnológica (desindustrialização) e a uma perda de competitividade com a reprimarização da economia, visualmente uma fragilidade ao equilíbrio econômico-financeiro. No entanto, deve-se ter um equilíbrio entre receitas e despesas, e a partir do resultado deste equilíbrio, reconduzir parte do saldo e reinvestir na geração de conhecimento científico e tecnológico para o desenvolvimento sustentável.

Nessa linha de raciocínio os resultados indicam que durante o período de 2008 e 2018 diversos avanços ocorreram nas políticas públicas de CT\&I no Brasil com vista a interromper esse ciclo de perde de competitividade. Destacamos as iniciativas da criação da Finep Inova Brasil, do Programa de Incentivo à Inovação Tecnológica Automobilística - Inovar-Auto (Decreto n ${ }^{\circ}$ 7.819/2012), da criação da Empresa Brasileira de Pesquisa e Inovação Industrial (Embrapii), do Novo Marco Legal de CT\&I - Lei $n^{\circ}$ 13.243/2016 e do Decreto n 9.283/2018 que regulamentou o novo Marco legal de CT\&I.

Os números anuais de formação de profissionais mestres e doutores sempre foram excelentes a nível nacional, contudo existe um déficit de formação de pessoas para as áreas de engenharia, ciências exatas e da terra. Essa realidade é agravada principalmente pela crise financeira recente que levou o fechamento de muitas empresas de base tecnológica. Um ponto que merece um olhar diferenciado é a entrada dos profissionais de pós-graduação nas empresas. De longe o estreitamento das relações entre empresas e as universidades para absorção dos profissionais precisa ser amadurecido, o país carece de profissionais qualificados nas indústrias de tecnologia intensiva, sejam elas nacionais como multinacionais. Políticas públicas direcionadas poderiam emergir neste sentido.

Do resultado do indicador de produção cientifica-tecnológica, a identificação das áreas temáticas em que o país mais se sobressaiu em termos de agregação de impacto poderiam ser ainda mais exploradas, buscando maximizar os resultados e auferir ganhos maiores ao país. Em contrapartida, não se pode deixar de lado as áreas temáticas estratégicas de ciência e tecnologia intensiva, principalmente aquelas em que o Brasil possui profissionais de referência. Nestes casos, instrumentos de incentivo e apoio, sejam de infraestrutura como de recursos financeiros, devem ser estabelecidos a fim de proporcionar prósperos caminhos da mesma forma que ocorreram com as áreas que hoje possuem destaque. 
Com relação ao percentual de investimento em Pesquisa e Desenvolvimento, as informações coletadas indicam que o Brasil precisa avançar na mesma direção que os países desenvolvidos. De fato, o compartilhamento do risco entre o setor público e privado precisa acontecer e ser maximizado, principalmente nas pesquisas que objetivam resultados disruptivos em áreas estratégicas para a sociedade brasileira. Entretanto não basta somente o compartilhamento de risco através do financiamento, seja ele a fundo perdido ou a juros subsidiados. É necessário acordo sólido entre as partes objetivando o devido planejamento de metas com gerenciamento de riscos e o estabelecimento de compras mínimas dos produtos desenvolvidos por parte do governo, ou colocando em prática os contratos de demandas de produtos tecnológicos (encomendas tecnológicas) com rodadas constantes e programadas, possibilidade fortalecida no novo Marco legal de CT\&I. As políticas de CT\&I precisam observar onde existe demanda e carência de desenvolvimento. É notória que as áreas intensivas de tecnologia estão sendo mais demandadas pela sociedade, seja nas áreas da saúde, de geração e acumulação de energia renovável, bem como nas áreas de tecnologia da informação e de infraestrutura e segurança. Desta forma, políticas públicas poderiam acontecer com foco nestas áreas.

Ficou demostrado pelo estudo dos cinco (5) indicadores o reflexo direto das decisões estratégicas na balança comercial. Ocorre uma desarticulação do sistema industrial com perda de participação na dinâmica econômica do país o que leva a uma perda de adensamento das respectivas cadeias produtivas, caracterizado pelos números da balança comercial, dos pedidos de patente e do desenvolvimento de conhecimento de impacto e formação profissional especializada, desaguando no baixo grau de inovação auferida pelo Brasil. É numérico o deslocamento do eixo dinâmico da economia para o exterior com a crescente importância das exportações de Commodities e de produtos de baixo valor agregado, que no período de 2008-2018 triplicou sua participação na balança comercial $(3,38)$, revelando a reprimarização da pauta exportadora brasileira. Os números dos demais indicadores de investimento de P\&D sem priorização de temas estratégicos; participação ínfima de pedidos de patentes genuinamente nacional; concentração de artigos em outras áreas de baixo impacto tecnológico; baixa absorção de profissionais de alta capacidade pelas empresas e; grau de inovação auferido, revelam o caminho a décadas adotado: política da entrada de indústrias multinacionais (globalização) e da importação de equipamentos e produtos da indústria tecnológica fina para suprir a demanda interna e a priorização da cadeia produtiva da agroindústria.

Diante deste diagnóstico a reflexão é, quais as iniciativas maduras que o governo deve implementar seja por políticas públicas, como por ajustes na economia e ou atuação nos demais setores como na justiça, para romper com este processo que se arrasta historicamente? Quais ações as empresas nacionais, públicas ou privadas, poderiam fazer no sentido de maximizar os resultados inovadores almejados e fortalecer as parcerias com as instituições de pesquisa? Os formuladores de políticas públicas não devem negligenciar os resultados que os indicadores trouxeram e devem continuar a desenvolver propostas alinhadas a realidade sócio-histórica do país e a realidade do capitalismo contemporâneo.

Deve-se também questionar esses indicadores de inovação e de aferimento da balança comercial, fazendo uma avaliação crítica das metodologias e teorias subjacentes, e elaboração de novas métricas pelos pesquisadores da área para se dimensionar com parâmetros mais efetivos tema tão importante para a elaboração de políticas desenvolvimentistas no Brasil. Outra reflexão crítica deve ser em cima dos diferentes estágios de desenvolvimentos de cada pais e sua localização dentro das cadeias produtivas globais, o que requer políticas setoriais adaptadas para cada em estágios, podendo ser estágios iniciais ou mais maduras, seguido por uma reorientação estratégica para políticas microeconômicas visando estágios posteriores. Os formuladores de políticas também podem executar uma combinação de estratégias de desenvolvimento baseado em certos índices de inovação, mesmo sabendo que determinada etapa deve ser protagonizada por uma política ou índices específicos. Além disso, as funções dos índices e de cada abordagem econômica variam dependendo da maturidade do sistema de inovação e da saúde da balança comercial. 


\footnotetext{
${ }^{1}$ Maiores detalhes no item 3.6 O Diagnóstico dos Impactos na Balança Comercial.

${ }^{2} \mathrm{FOB}$ - valores a preço de embarque, sem considerar fretes, seguros, impostos e taxas de embarque (IPEA, 2020).
}

\section{Referências}

ABMES, Associação Brasileira de Mantenedoras de Ensino Superior. Portaria $\mathbf{n}^{\mathbf{0}} \mathbf{8 0}$, de $\mathbf{1 6}$ de dezembro de 1998. Dispõe sobre o reconhecimento dos mestrados profissionais e dá outras providências. Diário Oficial da União (DOU) de 11 de janeiro de 1999. ABMES. 1998. Disponível em <https://abmes.org.br/arquivos/legislacoes/Portaria-Capes-80-1998-12-16.pdf>. Acesso em 01 mai. 2020.

ABPI. Dez anos de Política Industrial: Balanço e perspectivas. Org. Jackson De Toni. Agência Brasileira de Desenvolvimento Industrial. Brasília. 2015 . v. 1. 198 p. Disponível em <https://jacksondetoni.wordpress.com/2015/05/08/10-anos-da-politica-industrial-brasileira-balancoperspectivas-2004-2014/>. Acesso em 10 out. 2020.

ABPI; IPEA. Competitividade da engenharia de projetos nos setores de petróleo e gás, aeronáutico, naval e de infraestrutura de transporte. Org.: Luis Claudio Kubota ... [et al.]. Agência Brasileira de Desenvolvimento Industrial. Instituto de Pesquisa Econômica Aplicada Brasília. 242 p. 2014. Disponível em $<$ https://www.ipea.gov.br/portal/index.php?option=com_content\&view $=$ article\&id=24256>. Acesso em 10 out. 2020.

ARBIX, Glauco. Dilemas da Inovação no Brasil. In TURCHI, L. M. O., \& MORAIS, J. M. D. O. Políticas de Apoio a Inovação Tecnológica no Brasil: avanços recentes, limitações e propostas de ações. IPEA.

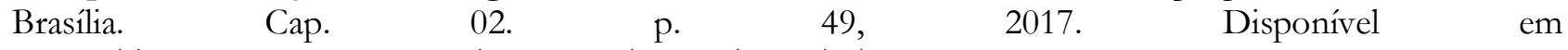
$<$ http://repositorio.ipea.gov.br/bitstream/11058/8125/1/Pol\%C3\%ADticas\%20de\%20apoio \%20\%C3\% A0\%20inova $\%$ C3\%A7\%C3\%A3o\%20tecnol\%C3\%B3gica\%20no\%20Brasil.pdf>. Acesso em 01 out. 2020.

AROCENA, Rodrigo; GÖRANSSON, Bo; SUTZ, Judith. Developmental universities in inclusive innovation systems: alternatives for knowledge democratization in the global south. Springer, 2017.

BADRAN, Adnan; BAYDOUN, Elias; HILLMAN, John R. (Ed.). Higher Education in the Arab World: Building a Culture of Innovation and Entrepreneurship. p. 385. Springer. 2020.

BAUER, M. W.; GASKELL, G. Pesquisa qualitativa com texto, imagem e som: um manual prático. Petrópolis. Vozes. Ed. 2a 2002.

BARBOSA, Denis Borges. Tratado da Propriedade Intelectual: Tomo I. Ed. 2a. Rio de Janeiro, RJ. Lumien Juris. 1087 p. 2017 a.

Lumien Juris. 766 p. $2017 \mathrm{~b}$.

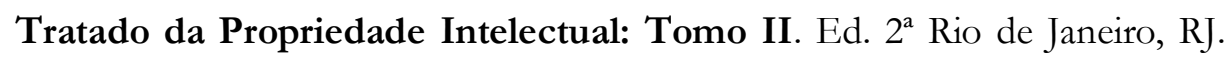

BELDERBOS, R.; DUVIVIER, F.; WYNEN, J. Innovation and export competitiveness: evidence from Flemish firms. [S.1.]: Steunpunt Ondernemen en International Ondernemen (STOIO). Working paper. 2009. Disponível em < https://core.ac.uk/download/pdf/34472046.pdf>. Acesso em 18 abr. 2019.

BUAINAIN, Antônio Márcio; BONACELLI, Maria Beatriz Machado; MENDES, Cássia Isabel Costa. Propriedade intelectual e inovações na agricultura. Org. Antônio Márcio Buainain, Maria Beatriz Machado Bonacelli, Cássia Isabel Costa Mendes. Brasília. Rio de Janeiro. CNPq, FAPERJ, INCT/PPED, IdeiaD. 2015. Disponível em <http://inctpped.ie.ufrj.br/pdf/livro/PI_e_Inovacoes_na_Agricultura.pdf>. Acesso em 23 de abr. 2020.

BRASIL. Relações Bilaterais: Estados Unidos da América. Ministério das Relações Exteriores. Brasília. 2020. Disponível em <http://www.itamaraty.gov.br/pt-BR/ficha-pais/5120-estados-unidos-da-america>. Acesso em 16 out. 2020.

CARDINALE, Roberto. Theory and practice of state intervention: Italy, South Korea and stages of economic development. Structural Change and Economic Dynamics, v. 49, p. 206-216, 2019.

CASTILHO, M. L. Mercado de trabalho e desindustrialização: uma leitura da economia brasileira no período de 1995 a 2013. A Economia em Revista - AERE, v. 25, n. 3, p. 97-107, 2017. Disponível em 
$<$ http://periodicos.uem.br/ojs/index.php/EconRev/article/download/50239/pdf_1/>. Acesso em 01. Out. 2020.

CASSANO, Francisco Américo et al. Política Externa Brasileira nos Governos FHC, Lula e Dilma: efeitos na balança comercial e no produto interno bruto brasileiro. Brazilian Journal of International Relations, v. 6, n. 1, p. 61-89. 2017. https://doi.org/10.36311/2237-7743.2017.v6n1.05.p61. Disponível em <http://www2.marilia.unesp.br/revistas/index.php/bjir/article/view/5986>. Acesso em 23 de abr. 2020.

CASSIOLATO, José E.; LASTRES, Helena MM. Políticas de inovação e desenvolvimento. Inovação no Brasil: avanços e desafios jurídicos e institucionais. Org. Diogo R. Coutinho, Maria Carolina Foss, Pedro Salomon B. Mouallem.- São Paulo. Blucher, 1 ed. 2017.

CGEE, Centro de Gestão e Estudos Estratégicos. Mestres e doutores 2015 - Estudos da demografia da base técnico científica brasileira. Brasília, DF. 348 p. 1 ed. 2016.

CIRANI, Claudia Brito Silva; CAMPANARIO, Milton de Abreu; SILVA, Heloisa Helena Marques da. A evolução do ensino da pós-graduação senso estrito no Brasil: análise exploratória e proposições para pesquisa. Avaliação: Revista da Avaliação da Educação Superior, v. 20, n. 1. 2015. https://doi.org/10.590/S141440772015000500011. Disponível em <https://www.scielo.br/scielo.php?pid=S141440772015000100163\&script=sci_abstract\&tlng=pt>. Acesso em 23 de abr. 2020.

CNI. Oportunidades para a indústria 4.0: aspectos da demanda e oferta no Brasil. Confederação Nacional da $\quad$ Indústria. $\quad$ Brasília. $\quad 58 \quad$ p. $2017 . \quad$ Disponível em <https://www.portaldaindustria.com.br/publicacoes/2018/2/oportunidades-para-industria-40-aspectosda-demanda-e-oferta-no-brasil/>. Acesso em 16 out. 2020.

Desafios para a indústria 4.0 no Brasil. Confederação Nacional da Indústria. Brasília. 34 p. 2016. Disponível em <https://www.portaldaindustria.com.br/publicacoes/2016/8/desafios-para-industria-40no-brasil/>. Acesso em 16 out. 2020.

CORNELL, Universidade; INSEAD; OMPI. Índice Global de Inovação de 2018: Energizando o Mundo com Inovação. Cornell INSEAD WIPO. Ithaca, Fontainebleau e Genebra. 133 p. 2018. Disponível em <https://www.globalinnovationindex.org/about-gii\#currentreports>. Acesso em 18 abr. 2019.

COSTA, Samuel Nogueira. Faces da Reestruturação Produtiva: Disputas por Representação e Alterações no Mundo do Trabalho. Editora Appris, p.221. 2020.

CRESWELL, J. W. Projeto de pesquisa métodos qualitativo, quantitativo e misto. Porto Alegre: Artmed. 2010.

CROSS, Di. THONSOM, Simon; SINCLAIR, Alexandra. Research in Brazil. A report for CAPES by Clarivate Analytics. Clarivate Analytics. 2017. Disponível em <https://www.capes.gov.br/images/stories/download/diversos/17012018-CAPES-InCitesReport-

Final.pdf $>$. Acesso em 18 abr. 2019.

DE NEGRI, João Alberto; SALERMO, Mario Sergio, CASTRO, Antonio Barros de. Inovações, Padrões Tecnológicos e Desempenho das Firmas Industriais Brasileiras. In: Inovações, padrões tecnológicos e desempenho das firmas industriais brasileiras/ João Alberto De Negri, Mario Sergio Salerno, organizadores. Brasília: IPEA, 2005. $728 \quad$ p. $\quad$ disponível em <https://www.ipea.gov.br/portal/images/stories/PDFs/livros/Inovacao_Padroes_tecnologicos_e_desem penho.pdf $>$. Acesso em 01 nov 2020.

DE NEGRI, F. Por uma nova geração de Políticas de Inovação no Brasil. In TURCHI, L. M. O., \& MORAIS, J. M. D. O. Políticas de Apoio a Inovação Tecnológica no Brasil: avanços recentes, limitações e propostas de ações. IPEA. Brasília. Cap.01. p. 25, 2017. Disponível em $<$ http://repositorio.ipea.gov.br/bitstream/11058/8125/1/Pol\%C3\%ADticas\%20de\%20apoio \%20\%C3\% A0\%20inova $\%$ C3\%A7\%C3\%A3o\%20tecnol\%C3\%B3gica\%20no\%20Brasil.pdf>. Acesso em 01 out. 2020.

DE NEGRI, F. et. al. Redução drástica na inovação e no investimento em P\&D no brasil: o que dizem os indicadores da pesquisa de inovação 2017. IPEA. Brasília. Nota Técnica No60, Abril de 2020. Disponível em <http://repositorio.ipea.gov.br/handle/11058/9877>. Acesso em 01 out. 2020.

DE NEGRI, J.A. Desempenho exportador das firmas industriais no Brasil: a influência da eficiência de escala e dos rendimentos crescentes de escala. Texto para Discussão n.997. Brasília: IPEA, 2003. 
Disponível

em

https: / www.ipea.gov.br/portal/index.php?option $=$ com_content\&view=article\&id=4213 $>$. Acesso em 01 out. 2020.

DE NEGRI, F. SQUEFF, H. S. Investimentos em P\&D do Governo Norte-Americano: evolução e principais características. IPEA. Brasília. Radar no 36 Tecnologia, Produção e Comercio Exterior. Dez. 2014. Disponível em <http://repositorio.ipea.gov.br/bitstream/11058/3316/1/Radar_n36.pdf >. Acesso em 16 out. 2020.

DELEIDI, Matteo; MAZZUCATO, Mariana. Directed innovation policies and the supermultiplier: An empirical assessment of mission-oriented policies in the US economy. Research Policy, v. 50, n. 2, p. 104151, 2021.

DELOITTE. Industry 4.0: Challenges and solutions for the digital transformation and use of exponential technologies. Deloitte. p.3. 2015 Zurique. Disponível em <https://www2.deloitte.com/content/dam/Deloitte/ch/Documents/manufacturing/ch-enmanufacturing-industry-4-0-24102014.pdf > . Acesso em 23 de abr. 2020.

DOU. Diário Oficial da União. Portaria no 389 de 23 de março de 2017. Dispõe sobre o mestrado e doutorado profissional no âmbito da pós-graduação strictosensu. 2017a. Disponível em <http://www.in.gov.br/materia/-/asset_publisher/Kujrw0TZC2Mb/content/id/20482828/do1-2017-0324-portaria-no-389-de-23-de-marco-de-2017-20482789>. Acesso em 01 mai. 2020.

Portaria $\mathrm{n}^{\circ} 131$ de 28 de junho de 2017. Dispõe sobre o mestrado e o doutorado profissionais. 2017b. Disponível em <http://www.in.gov.br/materia//asset_publisher/Kujrw0TZC2Mb/content/id/19150989/do1-2017-06-30-portaria-n-131-de-28-de-junhode-2017-19150907>. Acesso em 01 mai. 2020.

EDQUIST, Charles. Systems of innovation: technologies, institutions, and organizations. Edited By Charles Edquist. Science, technology and the International political economy series. 1997. Disponível em $<$ https://charlesedquist.files.wordpress.com/2015/06/science-technology-and-the-international-politicaleconomy-series-charles-edquist-systems-of-innovation_-technologies-institutions-and-organizationsroutledge-1997.pdf>. Acesso em 18 abr. 2019.

. The Systems of Innovation Approach and Innovation Policy: An account of the state of the art. In: Druid Conference, n. 2. 2001. [S.1.]. Anais... [S.1.:s.n]. p. 12-15. 2001. Disponível em <https://www.researchgate.net/publication/228823918>. Acesso em 18 abr. 2019.

. Towards a holistic innovation policy: Can the Swedish National Innovation Council (NIC) be a role model? Research Policy. Volume 48. Issue 4. 2019. Pages 869-879. ISSN 0048-7333. 2019. Disponível em <https://doi.org/10.1016/j.respol.2018.10.008>. Acesso em 01 nov 2020.

ESPOSITO, Mauricio. Desindustrialização no Brasil: uma análise a partir da perspectiva da formação nacional. Revista da Sociedade Brasileira de Economia Política, 46. Jan-abr. 2017. Disponível em < http://www.revistasep.org.br/index.php/SEP/article/view/293>. Acesso em 01 out. 2020.

ETZKOWITZ, Henry; ZHOU, Chunyan. Hélice tríplice: inovação e empreendedorismo universidadeindústria-governo. Estudos Avançados. 31 (90). 2017. https://doi.org/10.1590/s0103-40142017.3190003. Disponível em <https://www.scielo.br/scielo.php?script=sci_arttext\&pid=S0103-40142017000200023> Acesso em 18 abr. 2019.

FACCIN, Kadígia; BORTOLASO, Ingridi; BALESTRIN, Alsones. A Visão Relacional de Políticas de Ciência e Tecnologia: o Caso do Programa Brasileiro CI Brasil. Revista Eletrônica de Administração, Porto Alegre, RS, v. 22, n. 1, p. 226-251, jun. 2016. ISSN 1413-2311. Disponível em $<$ https://seer.ufrgs.br/read/article/view/54831/37607>. Acesso em 02 mai. 2020.

FERREIRA, Marcos José Barbieri. Plataforma aeronáutica militar. In: Mapeamento da Base Industrial de Defesa. ABDI - Agência Brasileira de Desenvolvimento Industrial: Ipea - Instituto de Pesquisa Econômica Aplicada. Brasília. $2016 . \quad$ Disponível em $<$ https://www.ipea.gov.br/portal/index.php?option $=$ com_content\&view $=$ article\&id=28101 $>$. Acesso em 23 de abr. 2020. 
FERREIRA, Patrícia Silva et al. Força de trabalho e capital intelectual no contexto da educação profissional, científica e tecnológica no Brasil. Revista Tecnologia e Sociedade, v. 13, n. 27, p. 1-23. 2017. DOI: 10.3895/rts.v13n27.2916. Disponível em < https://periodicos.utfpr.edu.br/rts/article/view/2916>. Acesso em 23 de abr. 2020.

FREEMAN, C. Technological infrastructure and international competitiveness. OECD ad hoc group on science, technology and competitiveness. Paris: OCDE. 1982. Disponível em <https://pdfs.semanticscholar.org/616c/37b605507530b4b450c078dc2d78fe37d223.pdf>. Acesso em 18 abr. 2019.

Pinter. 1987.

. Technology policy and economic performance - lessons from Japan. Londres: Frances

Diffusion: the spread of new Technologies to firms, sectors and nations. In: HEERTJE, A. (Ed.). Innovation, Technology and Finance. Oxford, Basil Blackwell. 1988.

FREEMAN, C; SOETE, L. Developing science, technology and innovation indicators: What we can learn from the past. Research Policy. Elsevier. v. 38. p.583-589. 2009. https://doi.org/10.1016/j.respol.2009.01.018.

Disponível

em <https://www.sciencedirect.com/science/article/abs/pii/S0048733309000237>. Acesso em 18 abr. 2019.

FURTADO, Celso. Essencial Celso Furtado. Org. Rosa Freire d'Aguiar. 1 ed. São Paulo. Penguin Classics Companhia das Letras. 2013.

GALINDO, Rueda F.; VERGER, F. OECD Taxonomy of Economic Activities Based on R\&D Intensity. OECD Science. Technology and Industry Working Papers. OECD Publishing, Paris. 2016. https://doi.org/10.1787/5jlv73sqqp8r-en. Disponível em <https://www.oecd-ilibrary.org/science-andtechnology/oecd-taxonomy-of-economic-activities-based-on-r-d-intensity_5jlv73sqqp8r-en>. Acesso em 18 abr. 2019.

GALLOTTI, M. E. R. et al. Cápsula de café: uma análise com base em teoria da inovação buscando agregar valor à balança comercial brasileira. Cadernos de Prospecção, v. 10, n. 2, p. 137, 2017.

GIL, Antônio Carlos. Como elaborar projetos de pesquisa.4 ed. São Paulo. SP. Atlas. 2002.

GIRARD, Bernard. Does "strategic patenting" threaten innovation? And what could happen if it did. SSRN. 2012. http://dx.doi.org/10.2139/ssrn.1985495. Disponível em <https://ssrn.com/abstract=1985495>. Acesso em 04 mai. 2020.

HIRATUKA, Célio; SARTI, Fernando. Transformações na estrutura produtiva global, desindustrialização e desenvolvimento industrial no Brasil. Revista de Economia Política, São Paulo, v. 37, n. 1, p. 189-207, mar. 2017. https://doi.org/10.1590/0101-31572016v37n01a10. Disponível em $<$ http://www.scielo.br/scielo.php?script=sci_arttext\&pid=S0101-

31572017000100189\&lng=pt\&nrm=iso >. Acesso em 04 mai. 2020.

INPI, Instituto Nacional de Propriedade Industrial. Indicadores de Propriedade Industrial - Edição 2018. INPI. 2019. Disponível em <http://www.inpi.gov.br/sobre/estatisticas>. Acesso em 18 abr. 2019.

IPEA, Instituto de Pesquisa Econômica Aplicada ou do Ministério do Planejamento, Desenvolvimento e Gestão. Políticas de apoio à inovação tecnológica no Brasil: avanços recentes, limitações e propostas de ações. Org. Lenita Maria Turchi, José Mauro de Morais. IPEA. Brasília. 2017. Disponível em $<$ https: / $/$ www.ipea.gov.br/portal/index.php?option=com_content\&view $=$ article\&id=30774\&Itemid=424 >. Acesso em 18 abr. 2019.

IPEA, Instituto de Pesquisa Econômica Aplicada ou do Ministério do Planejamento, Desenvolvimento e Gestão. Dicas. Dicionário de Conceitos. Brasília. 2020. Disponível em < http://www.ipeadata.gov.br/Default.aspx>. Acesso em 18 abr. 2019.

JULIEN, Pierre Andre. Empreendedorismo regional e economia do conhecimento. Editora Saraiva, 1 ed. 2017.

KEKLIK, Mümtaz. Schumpeter, Innovation and Growth: Long-cycle dynamics in the post-WWII American manufacturing industries. 1 ed. Routledge. 2018. 
LEYDESDORFF, L.; ETZKOWITZ, H. Emergence of a Triple Helix of university-industry-government relations. Science and Public Policy. At a workshop in Amsterdam. Vol. 23(5). p. 279-286. 1996. Disponível em <https://academic.oup.com/spp/article/23/5/279/1663475>. Acesso em 10 dez. 2018.

. The triple helix as a model for innovation studies. Science and

Public Policy. v. $25 . \quad$ n. 3. p. 195-203. 1998a. Disponível em <https://www.researchgate.net/publication/279550284_The_Triple_Helix_as_a_model_for_innovation_s tudies/download>. Acesso em 10 dez. 2018.

. Triple Helix of innovation: introduction. Science and Public

Policy. England. v. $25 . \quad$ n. 6. p. 358-364. 1998b. Disponível em $<$ https://www.researchgate.net/publication/279550435_Triple_Helix_of_innovation_Introduction>.

Acesso em 10 dez. 2018.

LITAN, R.E.; WYCKOFF, A.W.; FEALING, K.H. Capturing Change in Science, Technology, and Innovation: Improving Indicators to Inform Policy. National Academy of Sciences. National Academies Press. 2014. Disponível em <https://www.nap.edu/read/18606/chapter/1>. Acesso em 20 abr. 2019.

LUNDVALL, B. A. Innovation as an interactive process: from user-producer interaction to the national innovation systems. In: DOSI, G. et al. (Eds.). Technical change and economic theory. Londres. Pinter Publishers. 1988.

National systems of innovation: towards a theory of innovation and interactive learning. Londres. Pinter Publishers. 1992.

. National innovation systems: analytical concept and development tool. Industry and Innovation. v. 14, n. 1, p. 95-119. 2007. DOI: 10.1080/13662710601130863. Disponível em $<$ https://www.researchgate.net/publication/24081600_National_Innovation_Systems-

Analytical_Concept_and_Development_Tool>. Acesso em 10 dez. 2018.

MAIA, Bento Antunes de Andrade. Há desindustrialização no Brasil? Um estudo da abordagem clássica e de análises alternativas entre 1998 e 2014. Economia e Sociedade, v. 29, n. 2, p. 549-579, 2020.

MASON, G.; BISHOP, K.; ROBISON, C. Business Growth and Innovation. NESTA. Londres. 2009. Disponível em <https://media.nesta.org.uk/documents/business_growth_and_innovation.pdf $>$. Acesso em 10 dez. 2018.

MENDES, Dany Rafael Fonseca; OLIVEIRA, Michel Ângelo Constantino de; PINHEIRO, Adalberto Amorim. Política Nacional de Ciência, Tecnologia e Inovação: avaliação do marco regulatório e seus impactos nos indicadores de inovação. Revista de Empreendedorismo e Gestão de Pequenas Empresas, v. 2, n. 1, p. 22-46. 2013. http://dx.doi.org/10.14211/regepe.v2i1.49. Disponível em <https://www.regepe.org.br/regepe/article/view/49>. Acesso em 04 mai. 2020.

MARCONI, M. A., LAKATOS, E. Metodologia do trabalho científico. 7 ed. São Paulo: Atlas. 2011.

MCTIC, Ministério da Ciência, Tecnologia, Inovações e Comunicações. Dados abertos. 2019. Disponível em <http://www.mctic.gov.br/mctic/opencms/index.html>. Acesso em 18 abr. 2019.

MDIC, Ministério da Economia, Industria, Comercio Exterior e Serviços. Estatísticas de Comércio Exterior. 2019. Disponível em <http://www.mdic.gov.br/index.php/comercio-exterior/estatisticas-decomercio-exterior>. Acesso em 18 abr. 2019.

NELSON, Richard R. (Ed.). National innovation systems: a comparative analysis. New York. Oxford. Oxford University Press, 1 ed. 1993.

NEVES, José Luiz. Pesquisa Qualitativa - Características, Usos e Possibilidades. FEA.USP. Cadernos de Pesquisas em Administração, São Paulo. v.1. n. 3. 1996. Disponível em <http://www.hugoribeiro.com.br/biblioteca-digital/NEVES-Pesquisa_Qualitativa.pdf $>$. Acesso em 18 abr. 2019.

NSF, National Science Foundation. Universities Report Increased Federal R\&D Funding after 4-year Decline. R\&D Fields Revised for FY 2016. National Center for Science and Engineering Statistics, Higher Education Research and Development Survey. 2017. Disponível em <https://www.nsf.gov/statistics/2018/nsf18303/nsf18303.pdf>. Acesso em 18 abr. 2019 
OECD. The Organisation for Economic Co-operation and Development. The Organisation for Economic Co-operation and Development. Manual de Frascati 2002: Proposta de Práticas Exemplares para Inquéritos sobre Investigação e Desenvolvimento Experimental. OECD ILibrary. Barcelona. 2008. Disponível em $<$ https://doi.org/10.1787/9789264065611-pt>. Acesso em 18 abr. 2019.

The Organisation for Economic Co-operation and Development. New Sources of Growth Knowledge-Based Capital Driving Investment and Productivity in the 21st Century. OECD ILibrary. 2012. Disponível em <https://www.oecd.org/sti/50498841.pdf>. Acesso em 18 abr. 2019.

. The Organisation for Economic Co-operation and Development. Main Science and Technology Indicators. OECD ILibrary. 2019. Disponível em <https://www.oecd.org/sti/msti.htm>. Acesso em 18 abr. 2019.

PAIVA Júnior, F. G.; LEÃO, A. L. M. S.; MELLO, S. C. B. Validade e confiabilidade na pesquisa qualitativa em Administração. Ciências da Administração, v. 13, n. 31, p. 190-209. 2011. https://doi.org/10.5007/2175-8077.2011v13n31p190. Disponível em <https://periodicos.ufsc.br/index.php/adm/article/view/14719/0>. Acesso em 04 mai. 2020.

PARANHOS, Julia; CATALDO, Bruna; PINTO, Ana Carolina de Andrade. Criação, Institucionalização e Funcionamento dos Núcleos de Inovação Tecnológica no Brasil: Características e Desafios. Revista Eletrônica de Administração, Porto Alegre, RS, v. 24, n. 2, p. 253-280, set. 2018. ISSN 1413-2311. Disponível em <https://seer.ufrgs.br/read/article/view/84988>. Acesso em 02 mai. 2020.

QUINTELLA, Cristina M.; TEODORO, Auristela F. de Oliveira. Os ganhos econômicos diante da propriedade intelectual: retorno do investimento à sociedade. Gestão e Tecnologia para a Competitividade. 23-25 out. 2013. X SEGET 2013 - Simpósio de Excelência em Gestão e Tecnologia. 2013. Disponível em <https://www.aedb.br/seget/arquivos/artigos13/35018338.pdf>. Acesso em 16 out. 2020.

RAMOS, Milena Yumi. Internacionalização da pós-graduação no Brasil: lógica e mecanismos. Educaçao e Pesquisa: Revista da Faculdade de Educação da Universidade de São Paulo, São Paulo, v. 44, e161579. 2018. https://doi.org/10.1590/s1517-9702201706161579. Disponível em <https://www.scielo.br/pdf/ep/v44/1517-9702-ep-S1517-9702201706161579.pdf>. Acesso em 09 Abr. 2020.

ROCHA, Leonardo Andrade et al. O impacto dos investimentos em pesquisa \& desenvolvimento no desempenho das empresas. Revista de Economia Contemporânea, 20(1), 58-91. 2016. https://doi.org/10.1590/198055272013. Disponível em <https://www.scielo.br/scielo.php?pid=S141598482016000100058\&script=sci_abstract\&tlng=pt>. Acesso em 09 Abr. 2020.

RODRIGUES, Lásara Fabrícia. Fundamentos de Economia. Universidade Federal de Mato Grosso UFMT, Instituto Federal de Educação, Ciência e Tecnologia de Minas Gerais - IFMG. Ministério da Educação. Escola Técnica Aberta do Brasil - e-Tec Brasil. 127 p. 2012. Disponível em $<$ https://www2.ifmg.edu.br/ceadop3/apostilas/fundamentos-de-

economia/@@download/file/vers\%C3\%A3o_Final_-_Fundamentos_de_Economia_04.06.12.pdf>. Acesso em 10 ago. 2019.

RUIZ, Milton Artur; GRECO, Oswaldo Tadeu; BRAILE, Domingo Marcolino. Fator de impacto: importância e influência no meio editorial, acadêmico e científico. Revista brasileira de cirurgia cardiovascular. p. 273-278. 2009. https://doi.org/10.1590/S0102-76382009000400004. Disponível em $<$ https://www.scielo.br/scielo.php?script=sci_arttext\&pid=S0102-76382009000400004>. Acesso em 09 Abr. 2020.

SARTI, Fernando; HIRATUKA, Célio. Assimetrias no processo de internacionalização da economia brasileira no Século XXI. O Futuro do Desenvolvimento, Unicamp. p. 152-181. 2016.

SCARPELLI, Maíra Camargo; JUNIOR, Sérgio Kannebly. Mensuração e avaliação de indicadores de inovação. Gestão da Inovação e Empreendedorismo. Org. Geciane Silveira Porto. 1 ed. Rio de Janeiro. Elsevier. 472 p. 2013.

SCHUMPETER, Joseph A. Capitalismo, Socialismo e Democracia (1 ed., 1942). Rio de Janeiro: Zahar Editores S.A. 1984. 
Teoria do desenvolvimento econômico: uma investigação sobre lucros, capital, crédito, juro e o ciclo econômico (1 ed., 1934). Tradução de Maria Sílvia Possas. Coleção Os Economistas. São Paulo: Nova Cultural. 1997.

SMITH, K. Measuring innovation. The Oxford Handbook of Innovation. Oxford University Press. p. 148177. 2006.

TIDD, Joe; BESSANT, John. Gestão da Inovação. 5 ed. Porto Alegre. Bookman. 633 p. 2015.

TORINO, Emanuelle; VIDOTTI, Silvana Aparecida Borsetti Gregorio; SANT’ANA, Ricardo César Gonçalves. Ciclo de vida de dados no processo de publicação e acesso à produção científica. Encontro Nacional de Pesquisa em Ciência da Informação. Florianópolis. Anais [...] Florianópolis: Universidade Federal de Santa $\quad$ Catarina, 2019.20 Disponível em <https://conferencias.ufsc.br/index.php/enancib/2019/paper/viewFile/576/612. 2019>. Acesso em 01 out. 2020.

TURCHI, Lenita Maria; ARCURI, Marcos. Interação Institutos Públicos de Pesquisa e Empresas: Avaliação das Parcerias. In TURCHI, L. M. O., \& MORAIS, J. M. D. O. Políticas de Apoio a Inovação Tecnológica no Brasil: avanços recentes, limitações e propostas de ações. IPEA. Brasília. Cap. 03. p. 83, 2017. Disponível <http://repositorio.ipea.gov.br/bitstream/11058/8125/1/Pol\%C3\%ADticas\%20de $\% 20$ apoio $\% 20 \%$ C3\% A0\%20inova $\%$ C3\%A7\%C3\%A3o\%20tecnol\%C3\%B3gica\%20no\%20Brasil.pdf>. Acesso em 01 out. 2020.

UNCTAD, United Nations Conference On Trade And Development. Free market commodity price indices. $\begin{array}{lllll}\text { Nações } & \text { Unidas } & \text { (ONU). } & 2019 . & \text { Disponível }\end{array}$ <https://unctadstat.unctad.org/wds/TableViewer/tableView.aspx?ReportId=28769>. Acesso em 18 abr. 2019.

UIS, Institute For Statistics da UNESCO. How much does your country invest in R\&D? UNESCO. 2015. Disponível em < http://uis.unesco.org/apps/visualisations/research-and-development-spending/>. Acesso em 18 abr. 2019.

WEF, World Economic Forum. The Global Competitiveness Report 2018. Klaus Schwab. Cologny/Geneva. Switzerland, p. 671.WEF. 2018. Disponível em < https://www.weforum.org/reports/theglobal-competitveness-report-2018>. Acesso em 16 abr. 2019.

XIAO, Wen. Technological Progress and the Transformation of China's Economic Development Mode. Springer Books, 2020. 